\title{
DEVELOPMENT OF AN ADHESIVE CANDLE FILTER SAFEGUARD DEVICE
}

Final Report

(For the period September 29, 1999 through February 28, 2002)

Prepared for:

AAD Document Control

U.S. Department of Energy

National Energy Technology Laboratory

626 Cochrans Mill Road

PO Box 10940, MS 921-143

Pittsburgh, PA 15236-0940

Contract No. DE-AC26-99FT40677

Performance Monitor: Ted McMahon

Prepared by:

John P. Hurley Ann K. Henderson

Jan W. Nowok Michael L. Swanson

Energy \& Environmental Research Center University of North Dakota PO Box 9018 Grand Forks, ND 58202-9018 


\section{DOE DISCLAIMER}

This report was prepared as an account of work sponsored by an agency of the United States Government. Neither the United States Government, nor any agency thereof, nor any of their employees makes any warranty, express or implied, or assumes any legal liability or responsibility for the accuracy, completeness, or usefulness of any information, apparatus, product, or process disclosed or represents that its use would not infringe privately owned rights. Reference herein to any specific commercial product, process, or service by trade name, trademark, manufacturer, or otherwise does not necessarily constitute or imply its endorsement, recommendation, or favoring by the United States Government or any agency thereof. The views and opinions of authors expressed herein do not necessarily state or reflect those of the United States Government or any agency thereof.

This report is available to the public from the National Technical Information Service, U.S. Department of Commerce, 5285 Port Royal Road, Springfield, VA 22161; phone orders accepted at (703) $487-4650$.

\section{ACKNOWLEDGMENT}

This report was prepared with the support of the U.S. Department of Energy (DOE) National Energy Technology Laboratory Cooperative Agreement No. DE-AC26-99FT40677. However, any opinions, findings, conclusions, or recommendations expressed herein are those of the author(s) and do not necessarily reflect the views of DOE.

\section{EERC DISCLAIMER}

LEGAL NOTICE This research report was prepared by the Energy \& Environmental Research Center (EERC), an agency of the University of North Dakota, as an account of work sponsored by DOE. Because of the research nature of the work performed, neither the EERC nor any of its employees makes any warranty, express or implied, or assumes any legal liability or responsibility for the accuracy, completeness, or usefulness of any information, apparatus, product, or process disclosed, or represents that its use would not infringe privately owned rights. Reference herein to any specific commercial product, process, or service by trade name, trademark, manufacturer, or otherwise does not necessarily constitute or imply its endorsement or recommendation by the EERC. 


\section{TABLE OF CONTENTS}

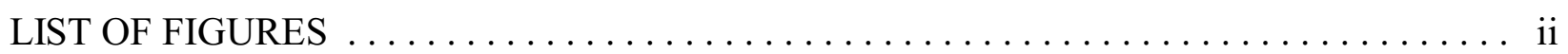

LIST OF TABLES $\ldots \ldots \ldots \ldots \ldots \ldots \ldots \ldots \ldots \ldots \ldots \ldots \ldots \ldots \ldots \ldots \ldots \ldots \ldots \ldots \ldots$

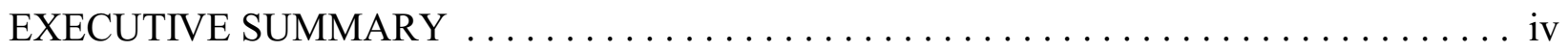

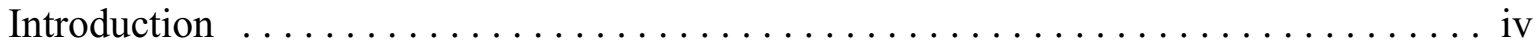

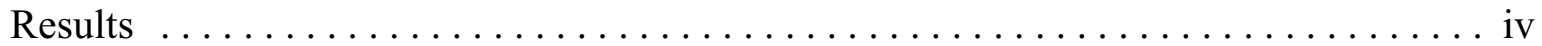

Conclusions $\ldots \ldots \ldots \ldots \ldots \ldots \ldots \ldots \ldots \ldots \ldots \ldots \ldots \ldots \ldots$

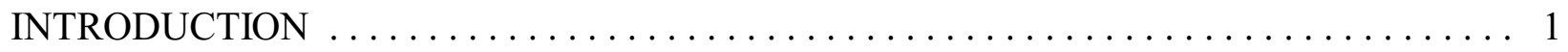

POROUS CERAMIC SUBSTRATES $\ldots \ldots \ldots \ldots \ldots \ldots \ldots \ldots \ldots \ldots \ldots \ldots$

COATING MATERIALS FOR COMBUSTION CONDITIONS $\ldots \ldots \ldots \ldots \ldots \ldots \ldots$

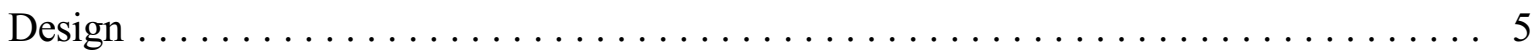

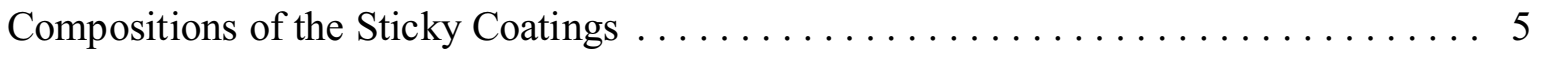

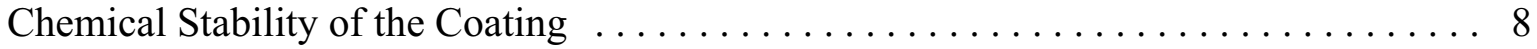

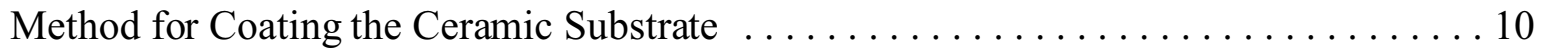

COATING MATERIALS FOR GASIFICATION CONDITIONS $\ldots \ldots \ldots \ldots \ldots \ldots \ldots \ldots$

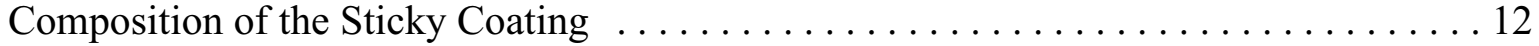

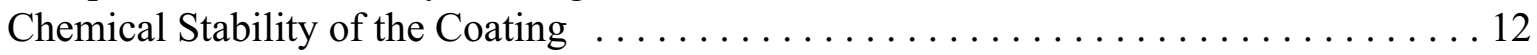

Method for Coating the Ceramic Substrate $\ldots \ldots \ldots \ldots \ldots \ldots \ldots \ldots \ldots$

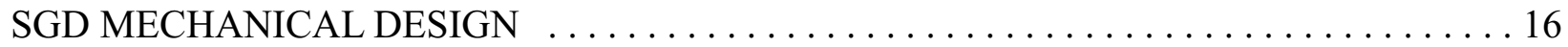

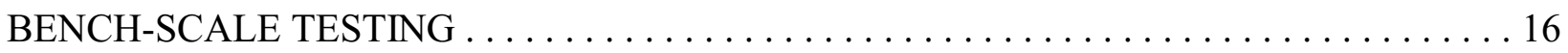

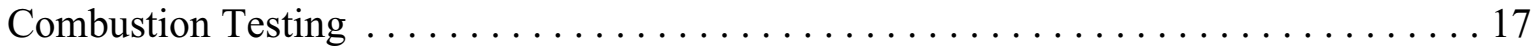

Description of the Bench-Scale Combustion Testing System … . . . . . . 17

PFBR Test Procedures . . . . . . . . . . . . . . . . . . . . . . . . 19

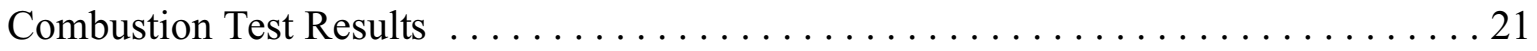

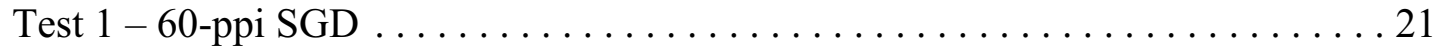

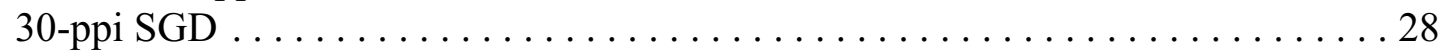

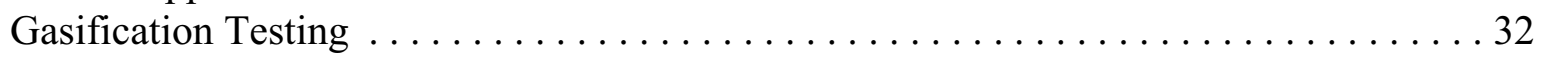

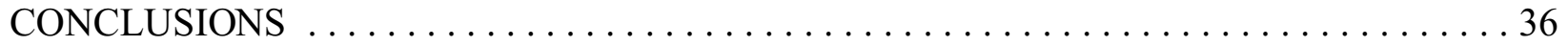

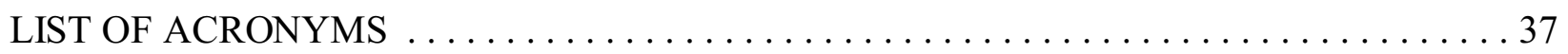

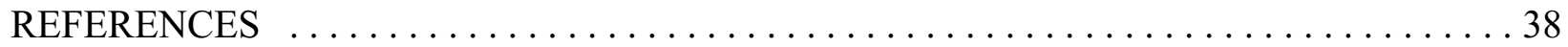




\section{LIST OF FIGURES}

1 The placement of an SGD at the outlet of a candle filter $\ldots \ldots \ldots \ldots \ldots \ldots \ldots \ldots$

2 Substrate weight versus pressure drop at $25 \mathrm{scfm}$ for 60 - and 80 -ppi disks and uncoated

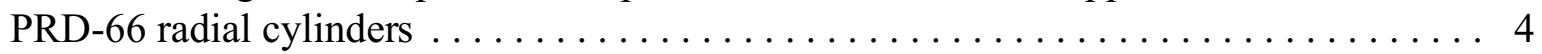

3 Phase diagram for the $\mathrm{K}_{2} \mathrm{SO}_{4}$ and $\mathrm{MgSO}_{4}$ system $\ldots \ldots \ldots \ldots \ldots \ldots \ldots \ldots \ldots \ldots \ldots \ldots \ldots$

4 Photograph of pellets of mixtures of Compound B mixed with Tidd dust and heated to

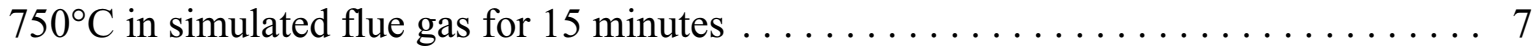

5 Weight change versus temperature for Compound B heated in all combustion gases except

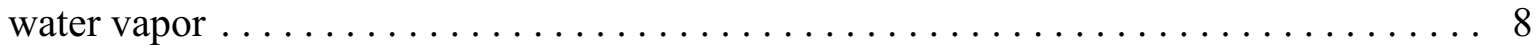

$6 \quad$ Weight change versus temperature for Compound B heated in all combustion gases

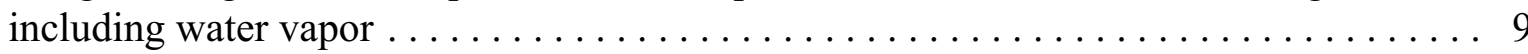

7 Weight loss versus temperature for alumina powder heated in simulated gasification

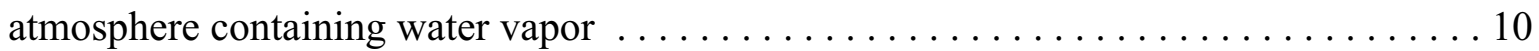

8 SEM photograph showing the remaining gel-derived Compound B precursor material in

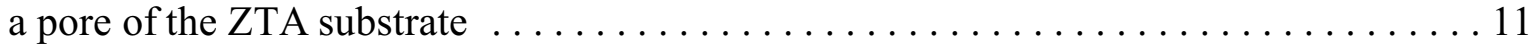

9 The heated stage XRD (a) heating and (b) cooling curves for the mixture of $90 \%$ by weight potassium sulfate and $10 \%$ magnesium sulfate that is fused to make Compound B. . . . 13

10 Surface of the silica-bonded $\mathrm{SiC}$ substrate after dipping once in $12 \%$ lithium formate

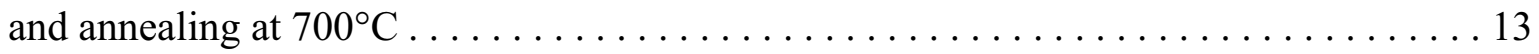

11 Surface of the silica-bonded $\mathrm{SiC}$ substrate after the second dip and anneal with $20 \%$

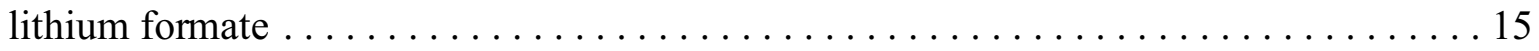

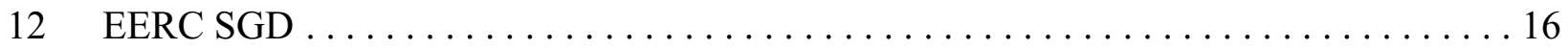

13 Schematic of the PFBR with the hot-gas filter vessel in place $\ldots \ldots \ldots \ldots \ldots \ldots 18$

14 Existing EERC tube sheet with backpulse and pressure tap nozzles $\ldots \ldots \ldots \ldots \ldots \ldots$

15 Closeup of the combustion SGDs in place on top of the tube sheet in the hot-gas filter

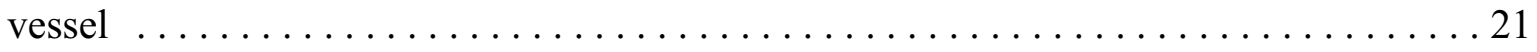

Continued... 


\section{LIST OF FIGURES (continued)}

16 PFBR test data from December 18 during the steady-state operation before any candle

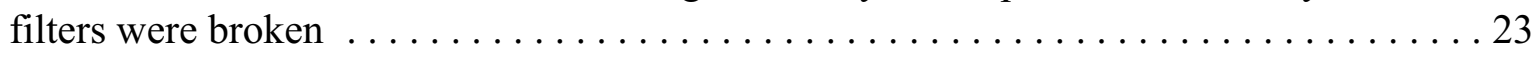

17 PFBR test data from December 21 after the first candle filter was broken $\ldots \ldots \ldots 23$

18 PFBR test data from December 26 after the second candle filter was broken . . . . . . . 24

19 SEM photograph of the surface of the EPA Method 5 particle filter from the test of the

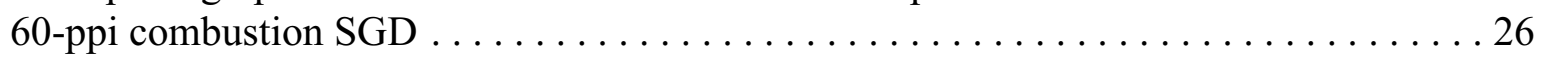

20 Cross section of one of the combustion SGDs tested in December $2000 \ldots \ldots \ldots$

21 SEM photograph of a pore containing ash in the densely filled section

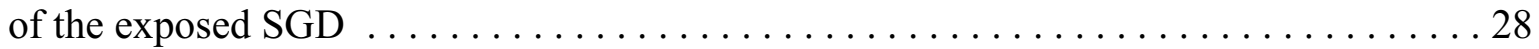

22 The filter vessel static pressure, differential pressures, and candle filter face velocity for

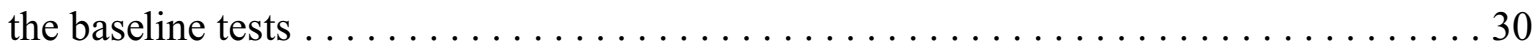

23 The filter vessel differential pressures and candle filter face velocity while firing coal

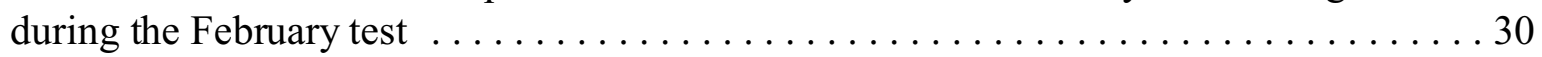

24 Dust loadings downstream of the SGDs as measured by the APS system . . . . . . . 31

25 Particle-size distributions downstream of the SGDs as measured by the APS system . . 32

26 Schematic of the $4-\mathrm{lb} / \mathrm{hr}$ CFBR for testing of the gasification SGD $\ldots \ldots \ldots \ldots$

\section{LIST OF TABLES}

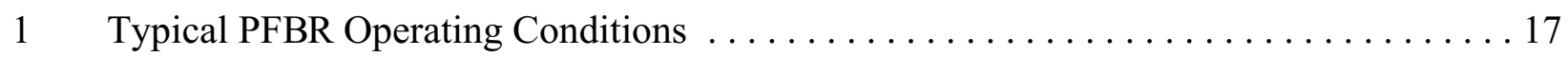

2 High-Temperature, High-Pressure Bench-Scale Filter Vessel Operating Capabilities . . 19

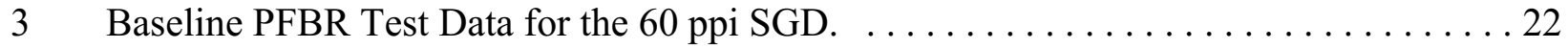

4 Baseline PFBR Test Data for the 30 ppi SGD $\ldots \ldots \ldots \ldots \ldots \ldots \ldots \ldots \ldots \ldots$

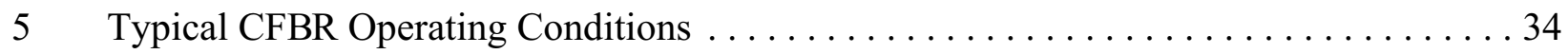




\section{DEVELOPMENT OF AN ADHESIVE CANDLE FILTER SAFEGUARD DEVICE}

\section{EXECUTIVE SUMMARY}

\section{Introduction}

In order to reach the highest possible efficiencies in a coal-fired turbine-based power system, the turbine should be directly fired with the products of coal conversion. Two main types of systems employ these turbines: those based on pressurized fluidized-bed combustors and those based on integrated gasification combined cycles. In both systems, suspended particulates must be cleaned from the gas stream before it enters the turbine so as to prevent fouling and erosion of the turbine blades. To produce the cleanest gas, barrier filters are being developed and are in use in several facilities. Barrier filters are composed of porous, high-temperature materials that allow the hot gas to pass but collect the particulates on the surface. The three main configurations of the barrier filters are candle, cross-flow, and tube filters. Both candle and tube filters have been tested extensively. They are composed of coarsely porous ceramic that serves as a structural support, overlain with a thin, microporous ceramic layer on the dirty gas side that serves as the primary filter surface. They are highly efficient at removing particulate matter from the gas stream and, because of their ceramic construction, are resistant to gas and ash corrosion. However, ceramics are brittle and individual elements can fail, allowing particulates to pass through the hole left by the filter element and erode the turbine.

Preventing all failure of individual ceramic filter elements is not possible at the present state of development of the technology. Therefore, safeguard devices (SGDs) must be employed to prevent the particulates streaming through occasional broken filters from reaching the turbine. However, the SGD must allow for the free passage of gas when it is not activated. Upon breaking of a filter, the SGD must either mechanically close or quickly plug with filter dust to prevent additional dust from reaching the turbine.

Production of a dependable rapidly closing autonomous mechanical device at high temperatures in a dusty gas stream is difficult because of problems with materials corrosion, dust leakage, and detection of filter failure. Therefore, the Energy \& Environmental Research Center is using its knowledge of the factors that make filter dust sticky at gas filtration temperatures to make a simple and inexpensive SGD that employs an adhesive yet thermodynamically stable coating on a highly porous ceramic substrate. The SGDs are placed on top of individual candle filters at the filtered gas exit. Upon failure of the filter, the dirty gas flows through the SGD where the adhesive surface rapidly and permanently traps dust particles, causing the device to plug and prevent the dust from reaching the turbine.

\section{Results}

The initial hypothesis of the work was that upon breakage of a filter, the adhesive coating would trap larger dust particles within the interpore openings of the ceramic substrate to block further dust flow through the SGD. To prevent the particles from being blown out of the device upon 
backpulsing, it was believed that the coatings should be either viscous or reactive with the dust to form a solid bond. To assure the long life of the coatings, it is necessary that they either have very low vapor pressures and reactivities with the gas stream or that the gas stream is already saturated with the components of the coating. Therefore, two coatings were developed. The one for gasification conditions is a viscous lithium silicate with a low vapor pressure. For combustion conditions, a low-viscosity potassium-magnesium sulfate material was developed which would react with larger limestone sorbent particles to form a solid to lock the particles in place. The combustion adhesive coating was based on materials that are known to be sticky and commonly exist in filter dust from coal-fired systems. The natural occurrence of the adhesive components in filter dust assures that they are saturated within the gas stream and so will not evaporate or change chemical form. The SGDs were tested in a bench-scale hot-gas filter system connected to both pressurized fluidized-bed combustion and gasification systems.

Tests in the bench-scale reactors showed that the combustion SGDs covered with the lowviscosity adhesive coating worked very well, plugging within minutes of a filter break. Only the bottom third of the SGD was filled with ash before plugging, indicating that very little dust would pass to the turbine in a power system. However, the more viscous coating used on the gasification SGD was not effective in trapping dust and blocking the gas and dust flow through the broken candle orifice.

\section{Conclusions}

The bench-scale tests of the SGDs showed that a porous ceramic substrate need only exhibit a pressure drop of 2 inches of water ( $3.7 \mathrm{~mm}$ of mercury), and it will still plug rapidly if an adhesive coating is applied to its surface. However, the adhesive is most effective if it has a low viscosity and wets the dust particles. Scanning electron microscope analyses indicate that the pore openings are not plugged with small numbers of large particles. Instead, large numbers of small particles derived from coal minerals fill the pore and are likely coated with the low-viscosity adhesive. The coating

causes them to agglomerate within the pore so that they are not removed on reverse-pulse cleaning and also prevents other particles from passing through the SGD. For the gasification SGD, a lowviscosity coating that is thermodynamically stable in the gas stream must be developed. 


\section{DEVELOPMENT OF AN ADHESIVE CANDLE FILTER SAFEGUARD DEVICE}

\section{INTRODUCTION}

In order to reach the highest possible efficiencies in a coal-fired turbine-based power system, the turbine should be directly fired with the products of coal utilization. Two main types of systems employ these turbines, those based on pressurized fluidized-bed combustors (PFBCs) and those based on integrated gasification combined cycles (IGCCs). In both systems, suspended particulates, or dust, must be cleaned from the gas before entering the turbine to prevent fouling and erosion of the turbine blades. To produce the cleanest gas, barrier filters are being developed and are in commercial use. Barrier filters are composed of porous, high-temperature materials that allow the hot gas to pass but collect the dust on the surface. The three main configurations are candle, crossflow, and tube. Both candle and tube filters have been tested extensively. They are primarily composed of coarsely porous ceramic that serves as a structural support, overlain with a thin, microporous ceramic layer on the dirty gas side that serves as the primary filter surface. They are highly efficient at removing particulate matter from the gas stream and, because of their ceramic construction, are resistant to gas and ash corrosion. However, ceramics are brittle, and individual elements can fail, allowing the particulates to pass through the hole left by the filter element and, possibly, erode the turbine.

Because of the possibility of occasional filter breakage, safeguard devices (SGDs) must be employed to prevent the dust streaming through broken filters from reaching the turbine. The SGD must allow for the free passage of gas when it is not activated, but upon breaking of a filter, the SGD must either mechanically close or otherwise plug to prevent dust from reaching the turbine. The SGD must use existing filter system seals, gaskets, fixtures, and assemblies as much as possible. It must also activate quickly when a candle filter has failed, preferably preventing dust concentrations downstream of the SGD from exceeding $1 \mathrm{ppmw}$ (1). In addition, the SGD must be able to operate in an inactive mode with minimal pressure drop, and its operation cannot be affected by repeated backpulse cleaning events of up to 3 psia $(155 \mathrm{mmHg})$ and $1 / 2$ second in duration.

Production of a rapidly closing autonomous mechanical device that is dependable at high temperatures in a dusty gas stream is difficult because of problems with materials corrosion, dust leakage, and detection of candle failure. Therefore, the Energy \& Environmental Research Center (EERC) is using its knowledge of the factors that make filter dust sticky at gas filtration temperatures to make an inexpensive SGD that rapidly and permanently plugs with dust upon filter failure. The SGD employs a sticky yet thermodynamically stable coating on a highly porous ceramic substrate. It would be placed at the outlet of a candle filter, as shown in Figure 1. The adhesive surface of the device will rapidly and permanently trap dust particles, causing the device to close the gas flow upon failure of a filter.

Just as different filter materials are used for combustion versus gasification conditions, different coatings will be used on an inert ceramic substrate to cover the typical range of conditions in PFBC (oxidizing) or IGCC (reducing) operating mode. For gasification, conditions in the Siemens-Westinghouse filter vessel at the Sierra Pacific Piñon Pine plant are being simulated in the 


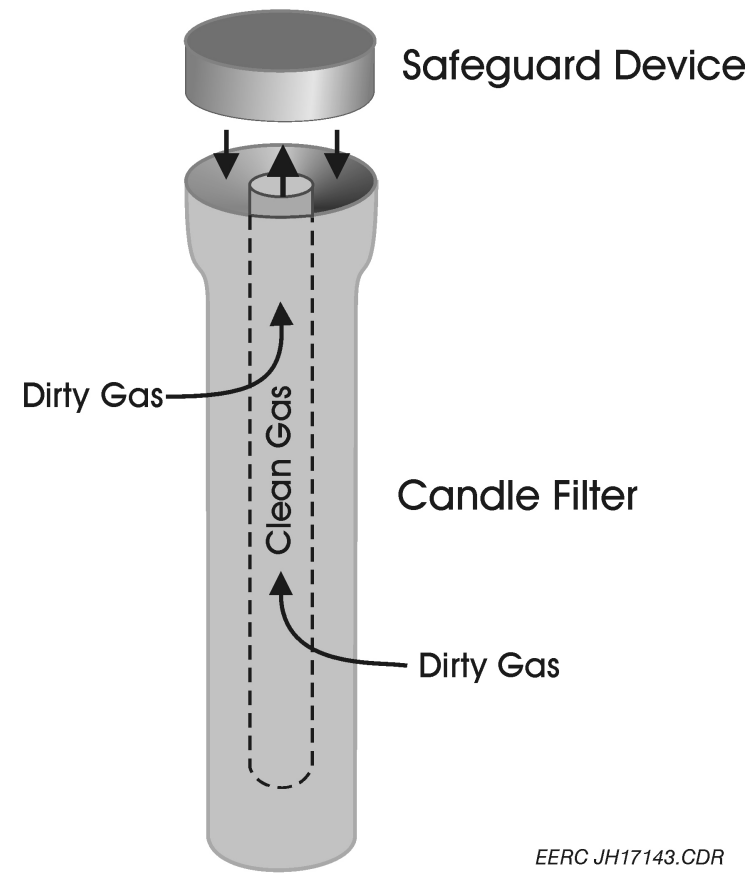

Figure 1. The placement of an SGD at the outlet of a candle filter.

testing. For combustion systems, the approximate conditions in the Siemens-Westinghouse particle filter used in conjunction with the Southern Company Services transport reactor being tested at the Power Systems Development Facility (PSDF) are employed. In both cases, however, the EERC SGD is composed of three main parts: the ceramic substrate, the adhesive coating, and the SGD housing. This report describes the development and laboratory testing of each of those parts as well as the bench-scale performance of both types of complete SGDs.

\section{POROUS CERAMIC SUBSTRATES}

The specifications for the porous ceramic substrates are that the pressure drop across the substrates must meet the requirements set forth by Siemens-Westinghouse, and the diameter should be the same as the top flange of a candle filter $(3 \mathrm{in}$.). The Siemens-Westinghouse standards for its filter vessel are for an SGD to not increase pressure drop across the filter vessel by more than 1 psi $(52 \mathrm{mmHg})$ during normal operation with a flow rate of $30 \mathrm{acfm}(850 \mathrm{lpm})$. At room temperature and pressure, that converts into approximately $30 \mathrm{scfm}(850 \mathrm{slpm})$ and $12 \mathrm{in}$. $(22.4 \mathrm{mmHg})$ of water pressure drop.

During the course of the program, we evaluated four different types of ceramic substrates. They included disks made from bonded coarse ceramic particles, ceramic foam made by gas foaming in a gel, radial-flow cylinders made from woven ceramic fiber, and disks made by coating a polymer sponge with a slurry made from fine ceramic particles. Refractron provided the disks made of mullite-bonded silicon carbide particles. The particles were typically $1 \mathrm{~mm}$ in diameter. The pressure 
drop was measured by passing air through a $25 / 8$-in. $(6.67-\mathrm{cm})$-diameter circle at the center of each disk. At $20 \mathrm{scfm}(566 \mathrm{slpm})$, the highest flow rate that could initially be tested in the EERC apparatus, a pressure drop of $11 \mathrm{in}$. $(20.5 \mathrm{mmHg})$ of water was measured. This equates to approximately $11 \mathrm{in} .(20.5 \mathrm{mmHg})$ at $26 \mathrm{scfm}(736 \mathrm{slpm})$ for a 3 -in. (7.6-cm)-diameter disk, which is perhaps barely acceptable using Siemens-Westinghouse standards, but was excluded from further testing because the pressure drop would likely increase after the sticky coating was applied.

We also evaluated a green cylinder of mullite foam from the University of Dayton. The cylinder was cut into two disks approximately $1 / 2 \mathrm{in} .(1.27 \mathrm{~cm})$ thick and 3 in. $(7.6 \mathrm{~cm})$ diameter, then fired according to the university's recommendations. During firing, the disks warped slightly and unevenly, and there was some slight cracking of the material. However, the disks could easily be ground flat to assure a good seal in the SGD assembly. The pressure drop measured for the disks was approximately 6 in. $(15.2 \mathrm{~cm})$ of water for a $25 / 8$-in. $(6.67-\mathrm{cm})$-diameter circle at $20 \mathrm{scfm}(566 \mathrm{slpm})$, which translates into 6 in. $(15.2 \mathrm{~cm})$ at $26 \mathrm{scfm}(736 \mathrm{slpm})$ for a 3 -in. $(7.6-\mathrm{cm})$ disk. Although the pressure drop was low, the pore size was very uneven, and some were large fractions of the thickness of the disk. Large pores (relative to the disk thickness) are not suitable in an SGD because dust particles could penetrate easily if a few of the large pores were linked. Therefore, this material was dropped from further consideration.

The third ceramic substrate material was a cylinder of woven PRD-66 candle filter material without the membrane coating, provided by Honeywell Advanced Composites. If this type of substrate were used, one end would be capped with a metal plate and woven ceramic fiber gasket, the open end would be butted to the open end of the candle filter and sealed with another woven ceramic fiber ring gasket, and the sides of the cylinder would be used as the porous SGD. A great advantage of this configuration is the higher surface area as compared to a flat disk, as much as four times greater for a 4-in. (10.2-cm)-tall cylinder. Measurements of the pressure drop across a cylinder of PRD-66 filter material without the fine membrane indicate that it would be suitable for an SGD. The material appears very strong, and the pressure drop across a 4-in. (10.2-cm)-long, 13/4-in. (4.45-cm)-i.d., 21/4-in. (5.72-cm)-o.d. cylinder was 10 in. of $\mathrm{H}_{2} \mathrm{O}(18.7 \mathrm{mmHg})$ at an airflow rate of $25 \mathrm{scfm}(708 \mathrm{slpm})$. Although this is barely acceptable, Honeywell has indicated that it can use the same weave pattern on a larger mandrel to make a cylinder with a larger inner diameter and a 3-in. $(7.6-\mathrm{cm})$ o.d. This would make both the inner surface area and the pores larger and reduce the pressure drop accordingly.

One concern was that the PRD-66 is made of alumina-coated fiberglass, and it is possible that the sticky combustion coating made of potassium and magnesium sulfate (described in the following section of this report) may corrode the fiberglass during operation. Therefore, a piece of PRD-66 was coated with the sticky combustion coating and fired at $750^{\circ} \mathrm{C}$ for four days in simulated flue gas. Scanning electron microscope (SEM) analyses indicate no reaction between the compound and either the alumina coating or the fiberglass material. Therefore, one dozen pieces of the uncoated filter material, cut from a single 1.5-meter candle, were ordered. They had average dimensions of 3.9-in. (909-cm)-long by 2.9 -in. $(7.37-\mathrm{cm})$ o.d. by 0.2 -in. $(0.51-\mathrm{cm})$ wall. However, large variations in pressure drops were measured across each of the cylinders. Also, we were informed after receiving the cylinders that Honeywell had no further plans to manufacture these candle filters. Given the 
pressure drop variability, and with no possibility of future supply, these substrates were dropped from further testing.

The last type of substrate tested was ceramic sponges made by Porvair-Selee by coating polymer sponges with a fine ceramic powder slurry, followed by curing and firing. Six different ceramic sponge materials were investigated. They included 30-, 60-, and 80-pore per inch (ppi) zirconia-toughened alumina (ZTA) for the combustion SGD and 30- and 60-ppi silica-bonded silicon carbide (SiC) and 60-ppi fused silica disks for the gasification SGD. The disks were typically $2 \frac{1}{2}$ to 3 in. $(6.35-7.62 \mathrm{~cm})$ in diameter and 1 in. $(2.54 \mathrm{~cm})$ thick.

In addition to different pore sizes and materials, densities of $14 \%-16 \%$ and $18 \%-20 \%$ for each ceramic type were tested for the effect of density on pressure drop in an airflow of $25 \mathrm{scfm}$ (708 slpm) at room temperature. All had acceptable pressure drops except for the fused silica disks for which many pores were skinned over by a thin ceramic coating. Figure 2 shows the effects of density (as indicated by substrate weight) on pressure drop for 60- and 80-ppi ZTA disks, along with data for the PRD-66 radial cylinders for comparison. The data show a good correlation between substrate weight and pressure drop for each type of substrate. It also shows the large variation in pressure drop across the PRD-66 cylinders and relatively small variation for the Porvair-Selee disks.

In general, as weight increases, the wall thickness increases at the expense of open pore diameter. As long as the pressure drop is acceptable, heavier walls are preferred because of the greater strength of the disks. Also, smaller pores are preferred since they will more likely trap particles upon breaking of the candle filter. However, the thickest 80-ppi walls are still thinner than the thinnest 60-ppi walls and the 80-ppi material was found to crumble excessively on handling, so

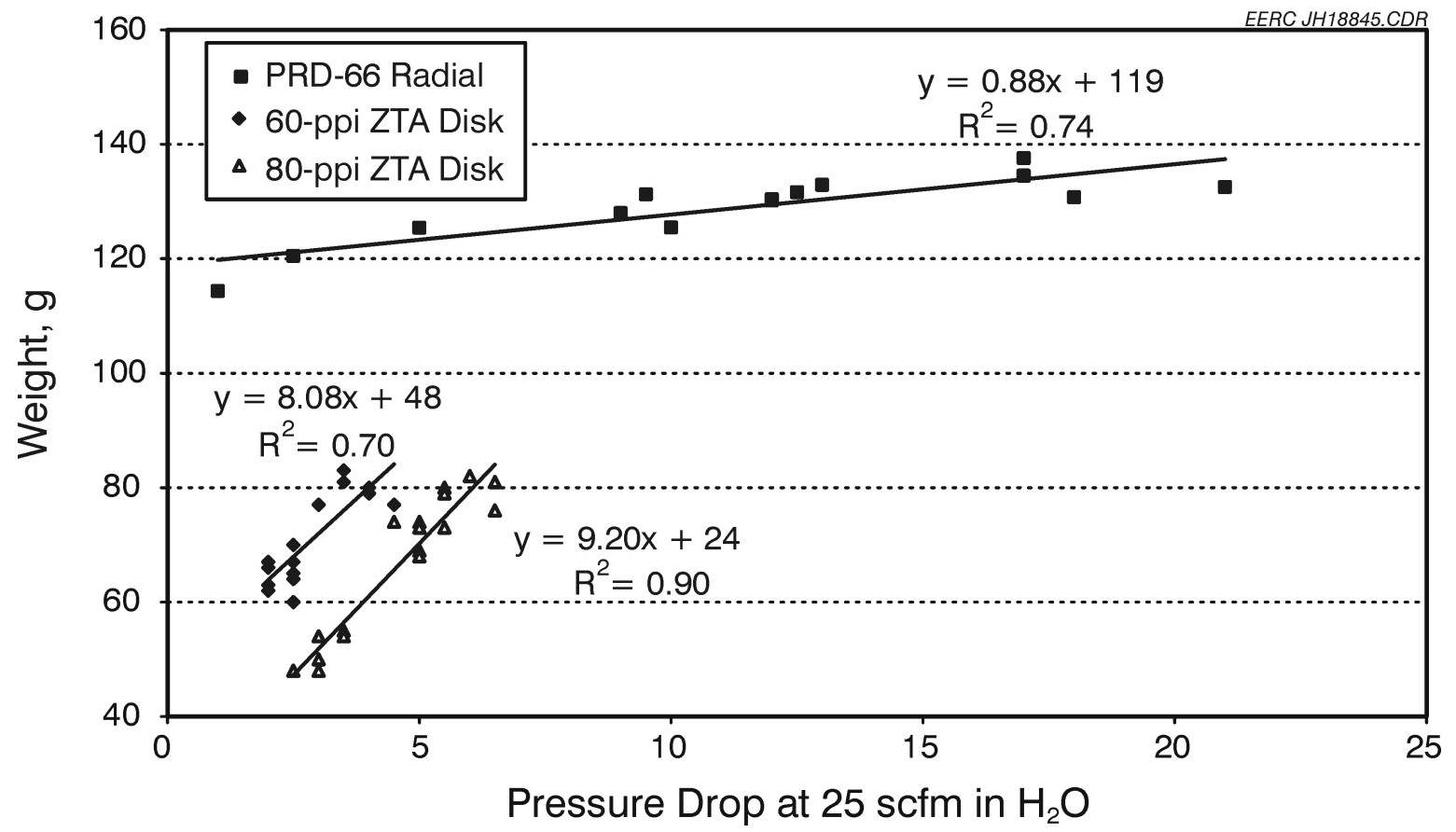

Figure 2. Substrate weight versus pressure drop at $25 \mathrm{scfm}$ for 60 - and 80-ppi disks and uncoated PRD-66 radial cylinders. 
the 80-ppi materials were dropped from further consideration. Also, the fused silica disks were also dropped from further consideration because of their excessively high pressure drops. Therefore, testing continued with the 30- and 60-ppi ZTA disks for the combustion SGD and the 30- and 60-ppi $\mathrm{SiC}$ disks for the gasification SGDs. Different substrate compositions were chosen for the combustion and gasification SGDs because of their better chemical compatibilities with the respective coating materials.

\section{COATING MATERIALS FOR COMBUSTION CONDITIONS}

\section{Design}

Operating conditions for the coating material developed for combustion systems were assumed to be approximately those found in the Siemens-Westinghouse filter vessel at the Southern Company Services PSDF when firing in combustion mode. Laboratory testing consisted of measurements of the thermodynamic stability of possible coating compounds and tests of the ability of the coating compounds to stick to filter vessel dust collected from the Westinghouse advanced particle filter used at the American Electric Power Tidd Station in May of 1995. This dust was considered by the operators to be a nonsticky material.

In order to reduce plugging of the SGD by the small amount of dust that normally passes through a filter during standard operation, sticky compounds were chosen that are especially effective in trapping sulfated limestone and dolomite sorbent particles, rather than ash formed from coal-derived minerals. Sorbent particles are targeted because previous proprietary research performed at the EERC has shown that larger dust particles entering a filter vessel tend to be dominated by the sorbent-derived particles, whereas smaller dust particles are dominated by the coal-mineral-derived ash (aluminosilicates and silicates). Therefore, it was thought that the SGD would only be active if the larger sorbent-derived dust particles enter the SGD when the filter has either failed or is seated improperly.

Targeting sorbent-based particles for preferential trapping was done by choosing sulfate-based materials for the coating compound. It is known through other proprietary work at the EERC that silicate-based coal ash particles were not initially wetted by liquid sulfates at hot-gas filter temperatures. Therefore, it was thought that smaller silicate ash particles that may leak through the candle filter during normal operation would be less likely to be retained within the SGD if a sulfatebased coating material were employed. This should similarly reduce the likelihood that the SGD will plug during normal operation of the candle filters.

\section{Compositions of the Sticky Coatings}

During the program, several different chemical systems were investigated. They included $\mathrm{Fe}_{2}\left(\mathrm{SO}_{4}\right)_{3}, \mathrm{FeSO}_{4}, \mathrm{Na}_{2} \mathrm{SO}_{4}, \mathrm{~K}_{2} \mathrm{SO}_{4}$, and $\mathrm{MgSO}_{4}$. The alkali sulfates were chosen because they naturally occur in filter dust so they must be thermodynamically stable, and the gas stream should be saturated with them so they should not be prone to evaporation. In addition, they all can be blended to make compounds with eutectic temperatures in the right range for the PSDF hot-gas filter 
vessel. The compounds were dried at $150^{\circ} \mathrm{C}$ before weighing and ground and mixed in a ball mill before reacting. The mixtures were heated in $10-\mathrm{mL}$ sintered alumina crucibles placed in a larger alumina tray. To determine the degree of sintering of the compounds and measure their thermodynamic stability as determined by weight change, they were heated in a tube furnace in a simulated combustion gas at a flow rate of $1 \mathrm{scfh}$ (approximately 1 furnace tube volume change every minute). The gas composition was $4 \% \mathrm{O}_{2}, 14 \% \mathrm{CO}_{2}$, and $1000 \mathrm{ppm} \mathrm{SO} \mathrm{S}_{2}$, with a balance of $\mathrm{N}_{2}$. No water vapor was included in these initial tests.

In general, the iron sulfates were less stable than the alkali sulfates so they were dropped from further testing. A mixture of $\mathrm{K}_{2} \mathrm{SO}_{4}$ and $\mathrm{Na}_{2} \mathrm{SO}_{4}$ named Compound $\mathrm{A}$ was effective at sintering Tidd filter dust at $800^{\circ} \mathrm{C}$. The eutectic temperature for the $\mathrm{K}_{2} \mathrm{SO}_{4}-\mathrm{Na}_{2} \mathrm{SO}_{4}$ chemical system is $832^{\circ} \mathrm{C}$, low enough to assure that the material would sinter well at $800^{\circ} \mathrm{C}$, but not completely fuse and, possibly, run off of the ceramic substrate (molten sulfates have very low viscosities). The tests were performed with a eutectic mixture of $\mathrm{K}_{2} \mathrm{SO}_{4}$ and $\mathrm{Na}_{2} \mathrm{SO}_{4}$ prepared and fused at $850^{\circ} \mathrm{C}$. After fusing, the compound was ball-milled and sieved to -30 microns. The sieved material was added to the Tidd dust in quantities of $20 \%$ and $50 \%$ by weight and shaken in a ball mill without a ball to assure good mixing. It was then heated in simulated flue gas without water vapor at $25^{\circ} \mathrm{C} / \mathrm{min}$ to $800^{\circ} \mathrm{C}$ and held for 15 minutes before cooling.

After cooling, it was found that the pure compound sintered well, but did not fuse. With as little as $20 \%$ of the Compound A mixed with the Tidd dust, a sintered mass formed that could easily be handled, although it was relatively easily crushed. With $50 \%$ of the compound, a hard pellet was formed that was much more difficult to break by hand. Its strength was similar to that of an aspirin tablet of a like size. Tidd dust with no compound did hold its shape somewhat, but the pieces were so weak that they could not be picked up with fingers. No weight loss was measured in the Compound A material to the nearest $1 / 10$ weight percent upon fusing at $850^{\circ} \mathrm{C}$ for 15 minutes or on holding at that temperature for 25.5 hours.

Although the tests of Compound A were successful at $800^{\circ} \mathrm{C}$, the Wilsonville facility often operates around $750^{\circ} \mathrm{C}$. Compound A was not effective at sintering the Tidd filter dust at that temperature. Therefore, a different material called Compound $\mathrm{B}$ was developed for use in the lower temperature range. Compound $\mathrm{B}$ is formed from $90 \% \mathrm{~K}_{2} \mathrm{SO}_{4}$ and $10 \% \mathrm{MgSO}_{4}$. As shown in Figure 3, one of the two eutectic temperatures for this system is $746^{\circ} \mathrm{C}$. Compounds were prepared at several ratios of $\mathrm{K}_{2} \mathrm{SO}_{4}$ and $\mathrm{MgSO}_{4}$ bracketing the ratio of the eutectic composition. They were made by mixing dried reagent-grade compounds, ball-milling, and fusing at $1080^{\circ} \mathrm{C}$ which is just above the melting temperature of the $\mathrm{K}_{2} \mathrm{SO}_{4}$. They were then ball-milled and sieved to -30 microns and mixed with the Tidd dust in ratios of $20 \%$ and $50 \%$ of the compounds. As was done with compound A, the compound-dust mixtures were shaken in a ball mill to mix them, then tapped into a crucible and heated to $750^{\circ} \mathrm{C}$ for 15 minutes in simulated flue gas. Figure 4 shows the sintered compound B and dust mixtures after removal from its crucible.

In contrast to the Compound A-dust mixtures, the Compound B-dust mixtures were much more sintered at $750^{\circ} \mathrm{C}$. They had approximately the same strength as the Compound A-dust mixtures sintered at $800^{\circ} \mathrm{C}$. The relatively high fragmentation of the $20 \% \mathrm{~B}$ pellet was caused by the difficulty in removing it from the crucible. A total of six different ratios of $\mathrm{K}_{2} \mathrm{SO}_{4}$ and $\mathrm{MgSO}_{4}$ were 

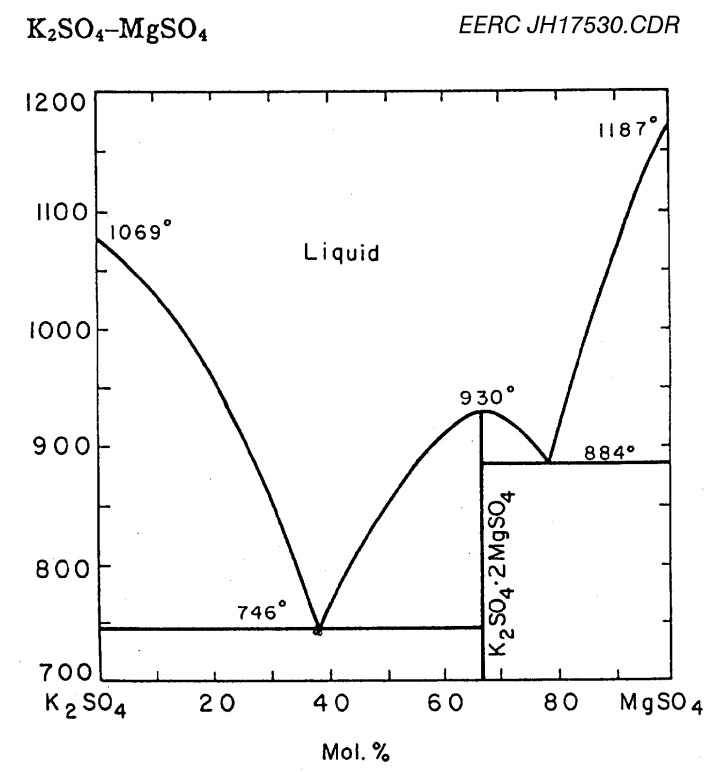

Fig. 2893.-System $\mathrm{K}_{2} \mathrm{SO}_{4}-\mathrm{MgSO}_{4}$.

S. M. Mikimov, N. I. Kri'lova, and A. G. Bergman, Akad. Nauk Uzbcksk. SSR, Tashkent, Inst. Khim. Trudy, 2, 100 (1949).

Figure 3. Phase diagram for the $\mathrm{K}_{2} \mathrm{SO}_{4}$ and $\mathrm{MgSO}_{4}$ system (taken from Volume 2 of Phase Diagrams for Ceramists, published by the American Ceramic Society [2]).

EERC JH16942.CDR

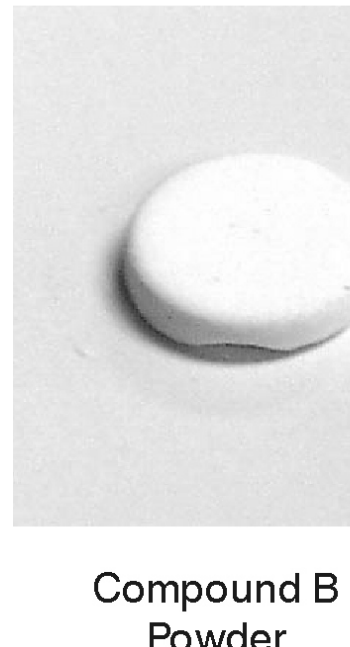

Powder

$20 \%$ B, $80 \%$ Ash

$50 \%$ B, 50\% Ash

Figure 4. Photograph of pellets of mixtures of Compound B mixed with Tidd dust and heated to $750^{\circ} \mathrm{C}$ in simulated flue gas for 15 minutes. 
tested. All sintered the dust well at $750^{\circ} \mathrm{C}$, but only Compound B did not produce melted material in the crucible containing the pure compound. Melted material would be detrimental to the performance of the SGD since it would be expected to flow off of the SGD during operation at temperature. Compound B was further tested by tilting the crucible containing the pure compound and reheating in simulated flue gas to $750^{\circ} \mathrm{C}$ for 1000 minutes (the limit of the furnace program) to see if melted material would flow to the bottom edge of the tilted crucible. Although the compound was more completely sintered than when heated for only 15 minutes, no separation of liquid was evident upon cooling. In addition, no weight gain or loss was detectable (to the nearest $0.05 \%$ ) for the compound, indicating that it is thermodynamically stable in a coal combustion gas environment. These tests indicate that for the Siemens-Westinghouse filter vessel operating near $750^{\circ} \mathrm{C}$, Compound B is the preferred sticky material, whereas for systems operating in the range of $800^{\circ} \mathrm{C}$, Compound A would be more preferable.

\section{Chemical Stability of the Coating}

To determine the influence of different flue gas constituents on the stability of Compound B, thermogravimetric analysis (TGA) was performed in a variety of atmospheres. The baseline gas composition simulated the $\mathrm{CO}_{2}, \mathrm{O}_{2}$, and $\mathrm{N}_{2}$ concentrations in a PFBC system. For different tests, $\mathrm{SO}_{2}$ and $\mathrm{H}_{2} \mathrm{O}$ were introduced, along with vaporization products from Tidd filter dust (by passing the baseline gas through a hot packed bed of the dust). The tests were done by heating at $5{ }^{\circ} \mathrm{C} / \mathrm{min}$ to $750^{\circ} \mathrm{C}$, then holding for 2 hours.

Figure 5 shows the weight as a function of temperature for a test performed in all gases except water vapor. The compound slowly gains approximately $1 \%$ weight while heating. It is not clear why

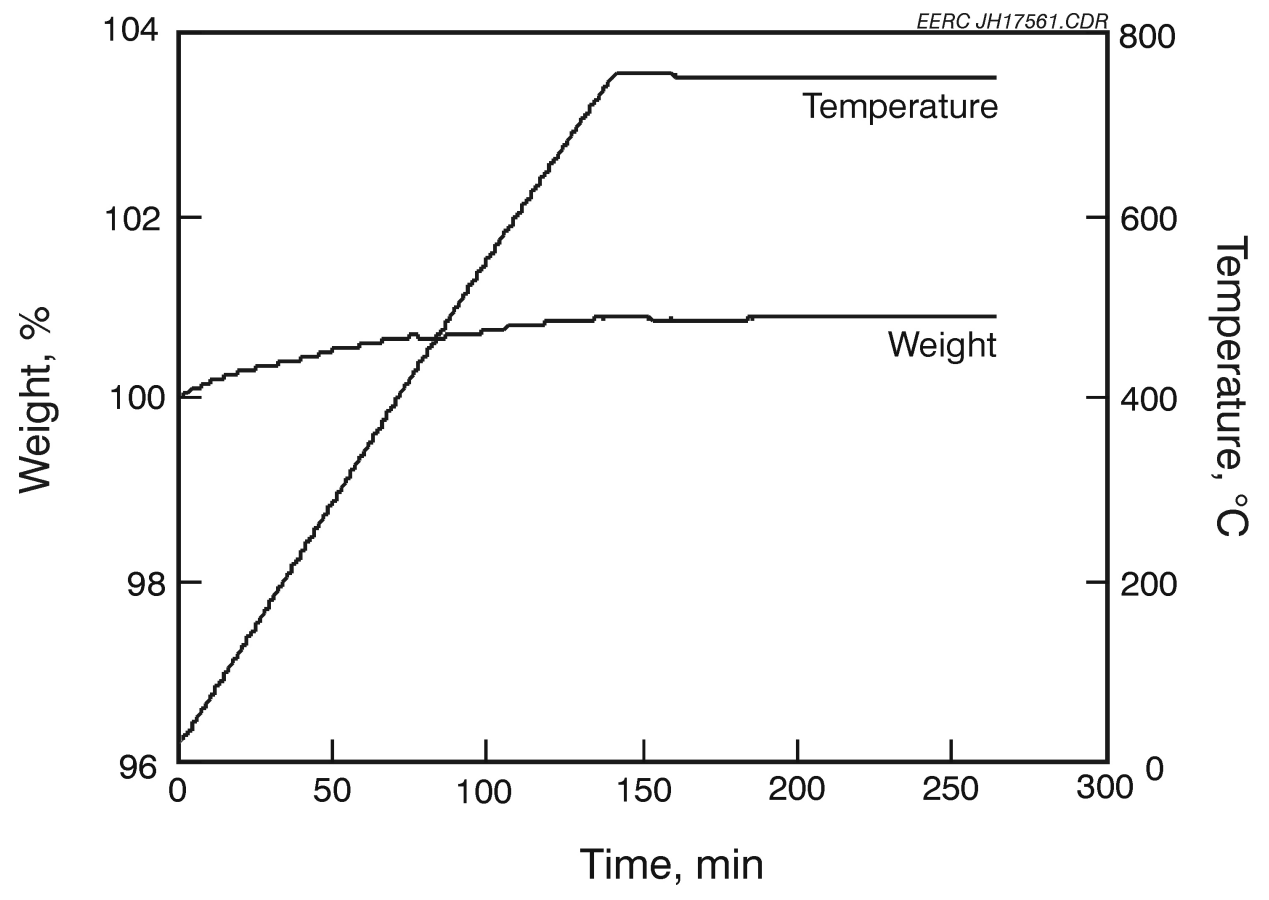

Figure 5. Weight change versus temperature for Compound B heated in all combustion gases except water vapor. 
the material gains weight, but may be a simple calibration effect. The Compound $\mathrm{B}$ weight remains stable (within $0.1 \%$ ) during the isotherm no matter what the atmosphere $\left(100 \% \mathrm{~N}_{2}\right.$ or $\mathrm{CO}_{2} / \mathrm{N}_{2} / \mathrm{O}_{2}$ or $\mathrm{SO}_{2} / \mathrm{N}_{2} / \mathrm{O}_{2} / \mathrm{CO}_{2}$ ), indicating that it does not slowly decompose or change form. Other tests showed a stronger weight loss on heating above $100^{\circ} \mathrm{C}$, indicating that Compound $\mathrm{B}$ absorbs some water at room temperature. However, the compound easily loses the absorbed moisture and performs the same on reheating as in original tests of dry Compound B.

Although very stable in simulated flue gas without water vapor, introduction of water vapor during TGA causes episodes of sudden weight loss, especially on heating above $200^{\circ} \mathrm{C}$. Figure 6 shows the TGA results for such a test. The TGA results suggest that water vapor causes particles of Compound B to "pop off" the surface during heatup. Weight losses of $1.3 \%$ during one test and 4\% in another occurred because of this pop-off. This may indicate that the outer surfaces of the SGD may lose a small amount of the coating during heating in a filter vessel. Any pop-off in the interior of the SGD would, however, be caught within the SGD and not lost from it.

It was not clear initially if the sudden weight loss in the presence of water vapor was due to the particles being blown off by puffs of steam or if there were small bursts of gas from the surfaces of the particles or explosive cracking due to sudden stress release. Visual observations indicated that the particles were in fact popping off of the TGA pan as the temperature was raised and not being blown off. To determine if the popping off was due to a chemical reaction unique to the gasification coating material, similar TGA tests were performed with alumina powder because alumina is known to be relatively inert in filter systems. As was true for the sticky compounds, when water vapor was introduced into the TGA, the alumina powder also began to pop off of the sample holder. Usually much more alumina came off than occurred for either of the sticky compounds, as shown in the TGA

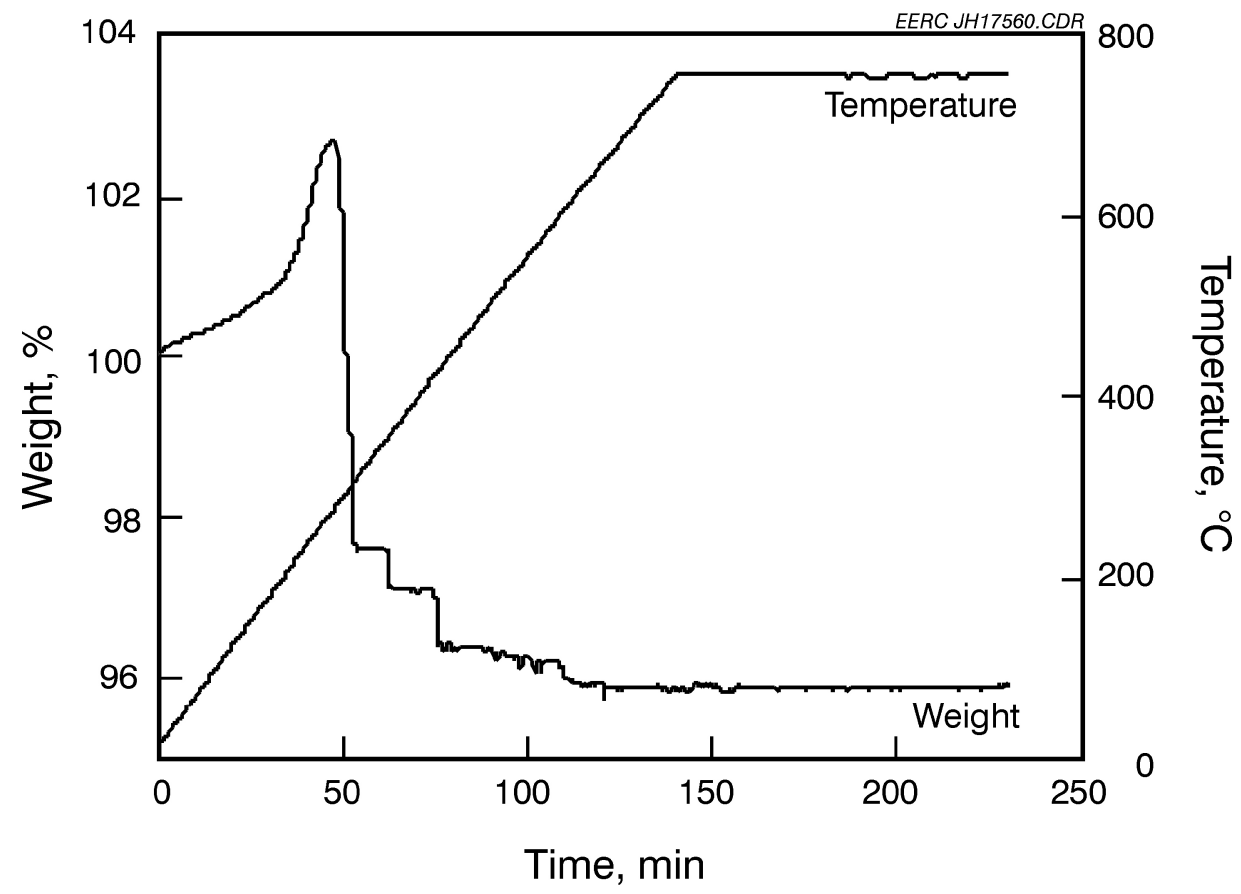

Figure 6. Weight change versus temperature for Compound B heated in all combustion gases including water vapor. 
graph presented in Figure 7. Because of the known stability of alumina in gas filtration systems, it is assumed that this explosive water loss phenomenon is a function of the very high surface area of the material (0.05-micron powder) and will likely not occur with larger structures such as the SGD. At a minimum, the sticky coating materials appear to be at least as stable under filtration conditions as alumina.

\section{Method for Coating the Ceramic Substrate}

The high solubility of the Compound B constituents in water indicated that dip-coating the porous ceramic substrates may be the easiest method to prepare the SGD. Initial tests of coating the Refractron disks indicated that dipping a hot disk in a boiling saturated solution of Compound B then drying it with hot air was appropriate because the disk appeared to dry so quickly, as indicated by no dripping of liquid from the disk when it was removed from the solution. However, the PRD-66 material and the Porvair-Selee foams dry more slowly because of the lower thermal mass of the structures and the greater tortuosity and smaller size of the pores. As reported previously, SEM analyses of the coated and fired PRD-66 material showed no corrosion of the substrate by the coating, but it did show some separation of the potassium sulfate from the magnesium sulfate during drying. The separation occurs because the solution is more saturated with the potassium salt than the magnesium salt, so the potassium salt precipitates first, followed by magnesium-rich material as the solution dries. During the slower drying that occurs with the finer-pore materials, the solution recedes, leaving potassium-rich material at the periphery and magnesium-rich material at the core of the solution droplet. Therefore, gelatin was added to the salt solution to prevent it from moving during drying.

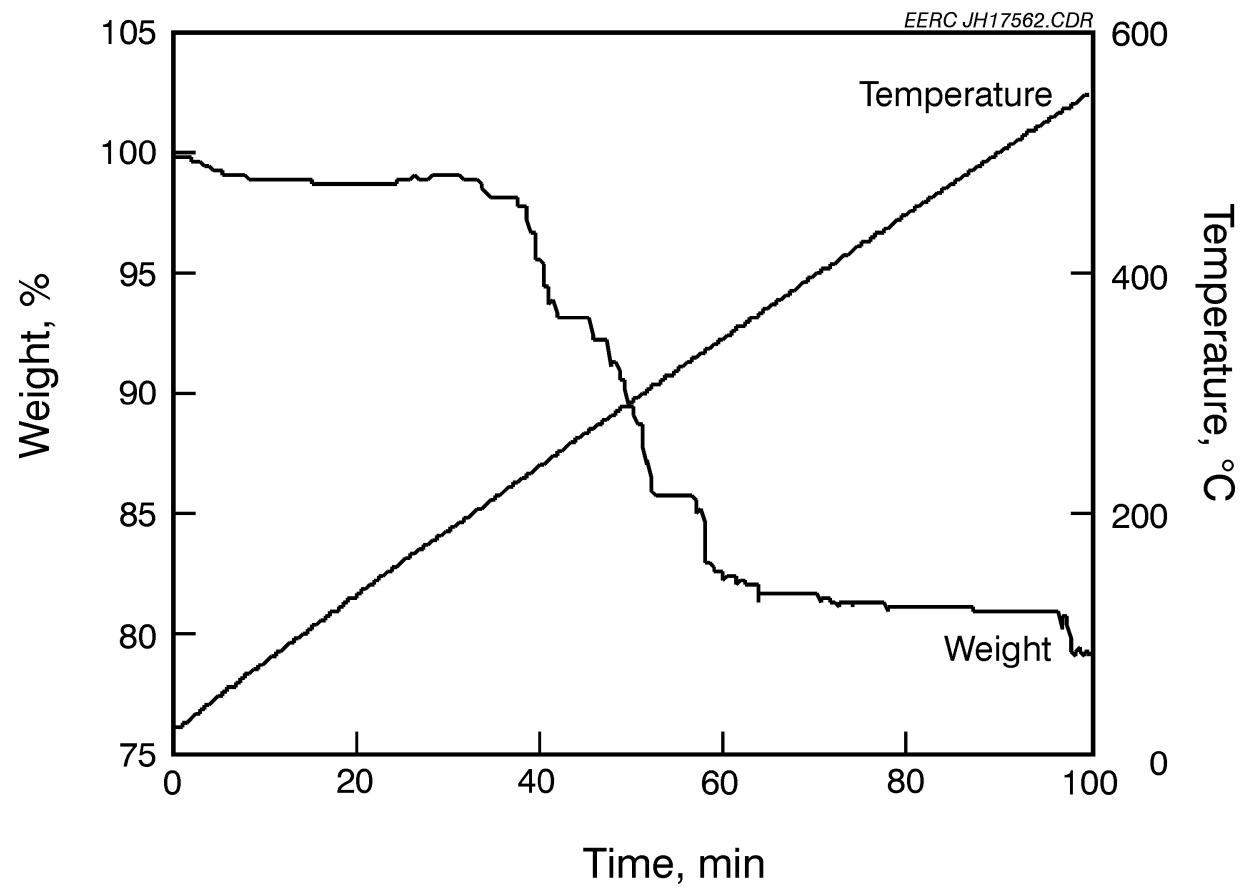

Figure 7. Weight change versus temperature for alumina powder heated in simulated gasification atmosphere containing water vapor. 
In tests of this method for coating the Porvair-Selee ceramic sponge material, enough gelatin was added to prevent the gel from melting at room temperature. A solution of 5 grams of a mixture of the Compound B salts to $100 \mathrm{~mL}$ of water was brought to a boil, and the gelatin dissolved in the solution. A piece of the ceramic sponge material was immersed in the solution, and after cooling to just above room temperature, a vacuum was pulled to help the liquid gel penetrate to all open porosity. The gel-permeated sponge was refrigerated overnight and then dried in a high vacuum over a day. Finally, the gelatin was burned out at $700^{\circ} \mathrm{C}$ in air. Figure 8 is a scanning electron micrograph showing the remaining salt material in a pore of the sponge. SEM analyses indicate that on a micronsized scale, the potassium and magnesium salts did not separate from each other during drying. However, the dried gelatin material mixture was not effective at sintering Tidd ash at $750^{\circ} \mathrm{C}$ as was the fused compound $\mathrm{B}$, indicating that simply drying the gel is not sufficient to activate the precipitated salts. In addition, pressure drop measurements indicated that the dried gel-filled pores exhibited an excessively high pressure drop. Therefore, the coated ceramic sponge material is fired at $1080^{\circ} \mathrm{C}$ both to activate the Compound $\mathrm{B}$ and fuse it to the walls of the substrate.

The adhesiveness and reactivity of the compound is enhanced if it is more amorphous than crystalline. To determine variations in the crystalline structure of the material during heating and cooling, precursor compounds were analyzed by x-ray diffraction (XRD) while heating in air to the above the liquidus temperature, followed by cooling to room temperature. Diffraction measurements were made at room temperature, then every $100^{\circ} \mathrm{C}$ from $700^{\circ} \mathrm{C}$ to $1000^{\circ} \mathrm{C}$, then every $20^{\circ} \mathrm{C}$ up to $1100^{\circ} \mathrm{C}$. The measurement temperatures were the same during cooling. Figure 9 shows the heating and cooling curves for the mixture of $90 \%$ by weight potassium sulfate and $10 \%$ magnesium sulfate that is fused to make Compound B. The heating curve shows that the potassium sulfate is orthorhombic at room temperature, but converts to hexagonal at $700^{\circ} \mathrm{C}$. Surprisingly, it has largely

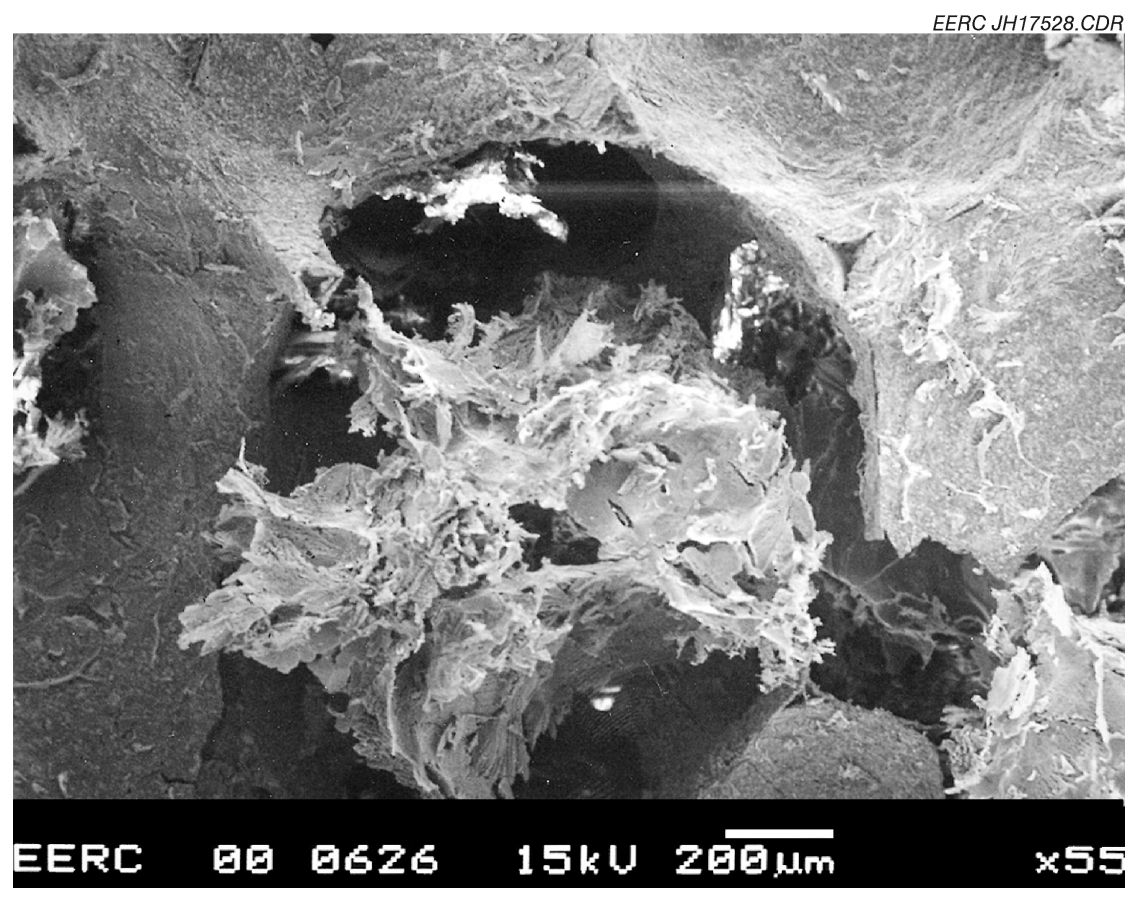

Figure 8. SEM photograph showing the remaining gel-derived Compound B precursor material in a pore of the ZTA substrate. 
lost all crystallinity by the time the mixture reaches $800^{\circ} \mathrm{C}$. It was thought from the analysis of the phase diagram that some crystalline potassium sulfate would be present up to the liquidus temperature. In contrast to the potassium sulfate, the magnesium sulfate is very weakly crystalline at room temperature, showing stronger peaks at $900^{\circ} \mathrm{C}$ where it was thought that it would be dissolved in the liquid. At $900^{\circ} \mathrm{C}$ and above, the presence of periclase (magnesium oxide) is indicated by the diffractogram. This was also unexpected because thermogravimetric analysis does not show a weight loss at this temperature which would occur as the sulfate converted to the oxide. Figure $9 \mathrm{~b}$ shows the cooling curve for the material. Note that the vertical axis has been significantly expanded to bring out the weak signals measured during this procedure. It shows only a weak periclase signal at all temperatures and that the compound does not recrystallize upon cooling, at least on the platinum strip used in the heated-stage XRD. This implies that after fusing, the material remains amorphous, and so can more readily flow and react with and bond filter dust particles, than if it were crystalline. Similar data for the dried gelatin material shows slightly different crystalline phases of potassium and magnesium sulfates while heating but a similar amorphous phase with a weak periclase signal after fusing.

\section{COATING MATERIALS FOR GASIFICATION CONDITIONS}

\section{Composition of the Sticky Coating}

Operating conditions for the sticky coating material developed for use in gasifiers are assumed to be approximately those of the filter vessel in use in the Siemens-Westinghouse filter vessel at the Piñon Pine fluid-bed gasifier. Thermodynamic equilibria calculations were used to determine the stability of calcium, sodium, and iron sulfides under gasification conditions in the temperature range of $370^{\circ}-540^{\circ} \mathrm{C}$. The calculations indicated that an initially proposed $\mathrm{Na}_{2} \mathrm{~S}-\mathrm{FeS}$ eutectic phase is unstable under these conditions and readily forms $\mathrm{Na}_{2} \mathrm{Ca}_{2} \mathrm{Si}_{3} \mathrm{O}_{9}$ and $\mathrm{NaCl}$ stable phases. Therefore, attention was turned to various alkali silicates. Literature data indicate a softening temperature of $500^{\circ} \mathrm{C}$ and a glass transformation temperature of approximately $450^{\circ} \mathrm{C}$ (3) for lithium silicate glass containing more than $15 \mathrm{~mol} \%$ lithia. Also, thermodynamic equilibrium calculations indicate that $\mathrm{Li}_{2} \mathrm{SiO}_{3}$ is stable under gasification conditions over a large temperature range. Therefore, it was decided to try to make the gasification SGD by lithiating a porous ceramic made with a silica-rich binder. In this type of SGD, the lithiated binder material would bond with ash particles that come to rest within the SGD through viscous flow sintering and not through chemical reaction.

\section{Chemical Stability of the Coating}

In order to determine the thermodynamic stability of the lithiated silicate materials in conditions similar to those in the Piñon Pine gasifier, parametric TGA was performed. Lithium silicate was prepared by mixing $99.9 \%$ silica powder with lithium formate solution and dried to make a mixture with $20 \mathrm{~mol} \%$ lithia. It was then sintered at $1200^{\circ} \mathrm{C}$ for 5 hours in air in a platinum crucible. After firing, the material was ground to a fine powder. A similar procedure was used to make lithiated aluminosilicate, except that $20 \%$ alumina powder was added to the silica before lithiating. This material was fired at $1400^{\circ} \mathrm{C}$ in air for 5 hours in a platinum crucible and then powdered after cooling. 


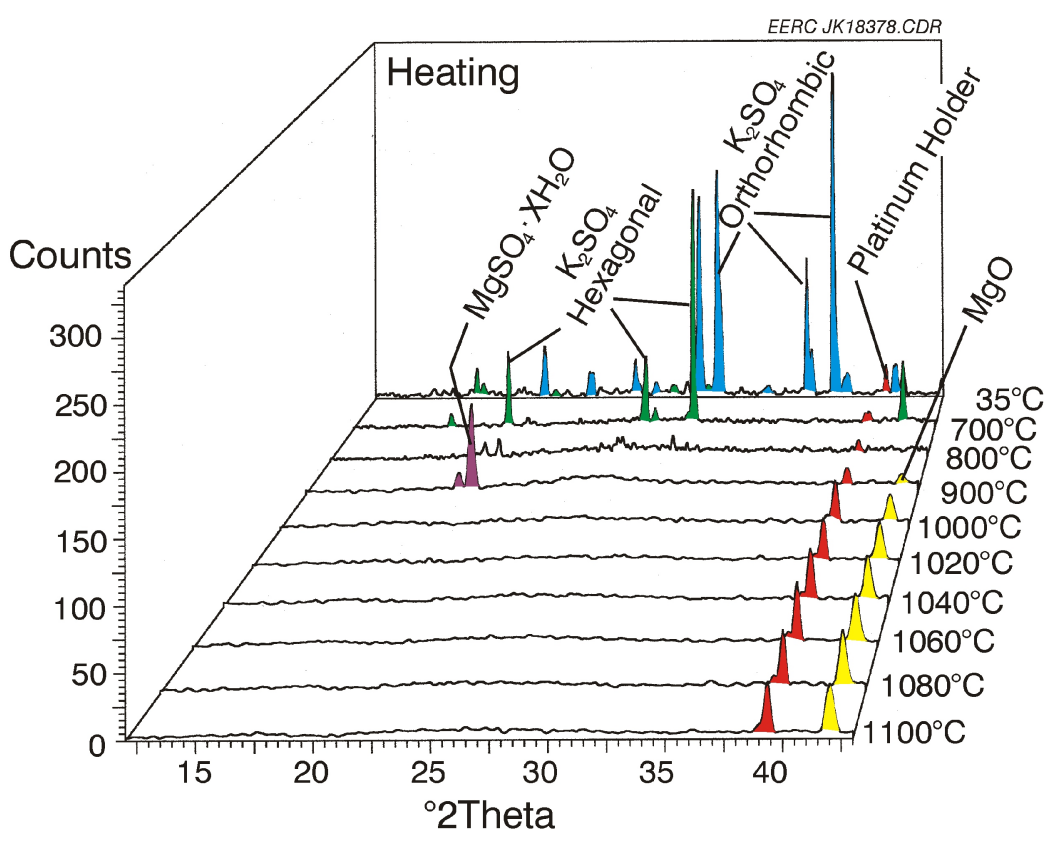

(a)

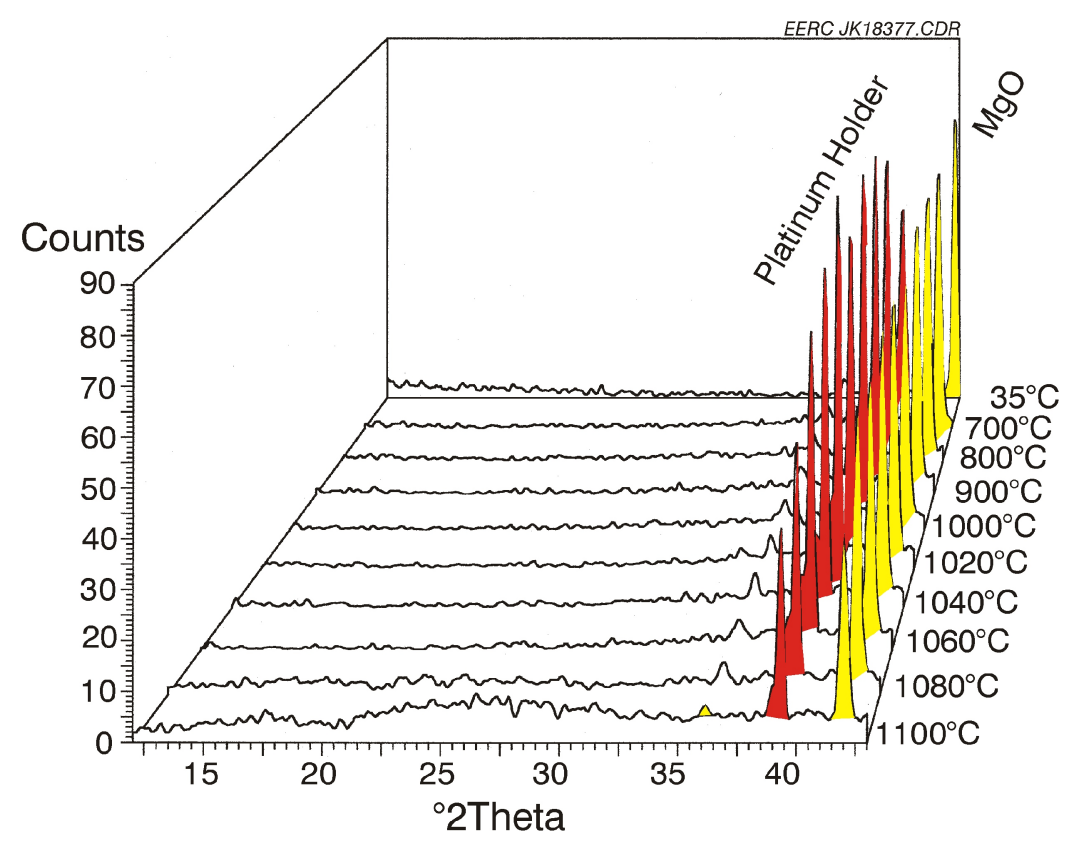

(b)

Figure 9. The heated-stage XRD (a) heating and (b) cooling curves for the mixture of $90 \%$ by weight potassium sulfate and 10\% magnesium sulfate that is fused to make Compound $\mathrm{B}$. 
During the TGA tests, the materials were heated in an atmosphere of $18 \% \mathrm{CO}_{2}, 16 \% \mathrm{H}_{2}, 26 \%$ $\mathrm{CO}, 40 \% \mathrm{~N}_{2}$, and $1000 \mathrm{ppm} \mathrm{H}_{2} \mathrm{~S}$, with and without $5 \%$ water vapor (started at $150{ }^{\circ} \mathrm{C}$ ). Most of the $\mathrm{N}_{2}$ was passed through a hot bed of gasifier ash within the TGA in order to enrich it with any volatile trace species that would be present in a hot-gas filter vessel. The samples were heated at $5^{\circ} \mathrm{C} / \mathrm{min}$ to $550^{\circ} \mathrm{C}$, then held for 2 hours. An inert sample (alumina chips) showed a slow weight gain totaling $0.7 \%$ during heatup, probably due to a calibration error. The lithiated aluminosilicate sample followed exactly the same curve as the inert material, demonstrating its chemical stability in a dry gasifier gas stream. When water vapor was added, starting at $220^{\circ} \mathrm{C}$, there were a series of small, sudden weight losses, dropping the weight to $99.4 \%$ of the original weight. This weight loss totals $0.6 \%$ of the original weight, or $1.3 \%$ if the normal weight gain is added. One lithiated silicate sample showed essentially identical behavior to the lithiated aluminosilicate when water was added. A duplicate lithiated silica test showed one large, sudden weight loss of $3 \%$ in the presence of water vapor because of the pop-off phenomenon. However, as described in the section of this report on the TGA tests of the combustion compound, an inert material behaved similarly. Therefore, we believe that the pop-off phenomenon in the presence of water vapor will not be detrimental to the performance of the SGD. These results indicated that lithiation of silica-rich binders in porous ceramics makes a chemically stable coating which the literature data indicated should be relatively sticky as a viscous molten glass.

\section{Method for Coating the Ceramic Substrate}

The SGDs were initially prepared with 30-ppi silica-bonded silicon carbide SGD disks. Higher ppi disks would have been preferred, but Porvair-Selee at that time did not make the silicon carbide disks with finer porosity. However, bench-scale testing of 30-ppi ZTA combustion SGDs showed that porosity was too high. Therefore, later in the program, Porvair-Selee was able to provide us with 60-ppi SiC disks which were used to make the gasfication SGDs for bench-scale tests, but in order to keep project costs down, SEM analyses of the coated 60-ppi SiC disks were not performed since they were assumed to be similar to the analyses of the 30-ppi disks presented here. Initially, the 30 -ppi SiC disks were dipped in an aqueous $12 \%$ lithium formate solution, then dried at $150^{\circ} \mathrm{C}$ in air before annealing at $700^{\circ} \mathrm{C}$ in air to form lithium silicate on the surfaces of the pores. However, initial tests with the $\mathrm{SiC}$ substrates indicated that the coating layer was relatively thin using this procedure. The SEM photograph in Figure 10 shows the surface of the substrate after impregnation with the $12 \%$ solution. Because lithium cannot be detected by $x$-ray analysis, we infer the coating presence by the crystalline-appearing phases at the surface of the ceramic. As the figure shows, the coating material is discontinuous using this procedure. Therefore, to increase the continuity and thickness of the layer, the gasification SGD substrates were each coated twice. This was done by dipping in a $20 \%$ lithium formate solution and annealing at $700^{\circ} \mathrm{C}$, then repeating the process. Figure 11 shows the appearance of the 30-ppi substrate after the second dip and anneal. As the figures indicate, the coating appears more continuous when using the $20 \%$ solution with multiple treatments. 


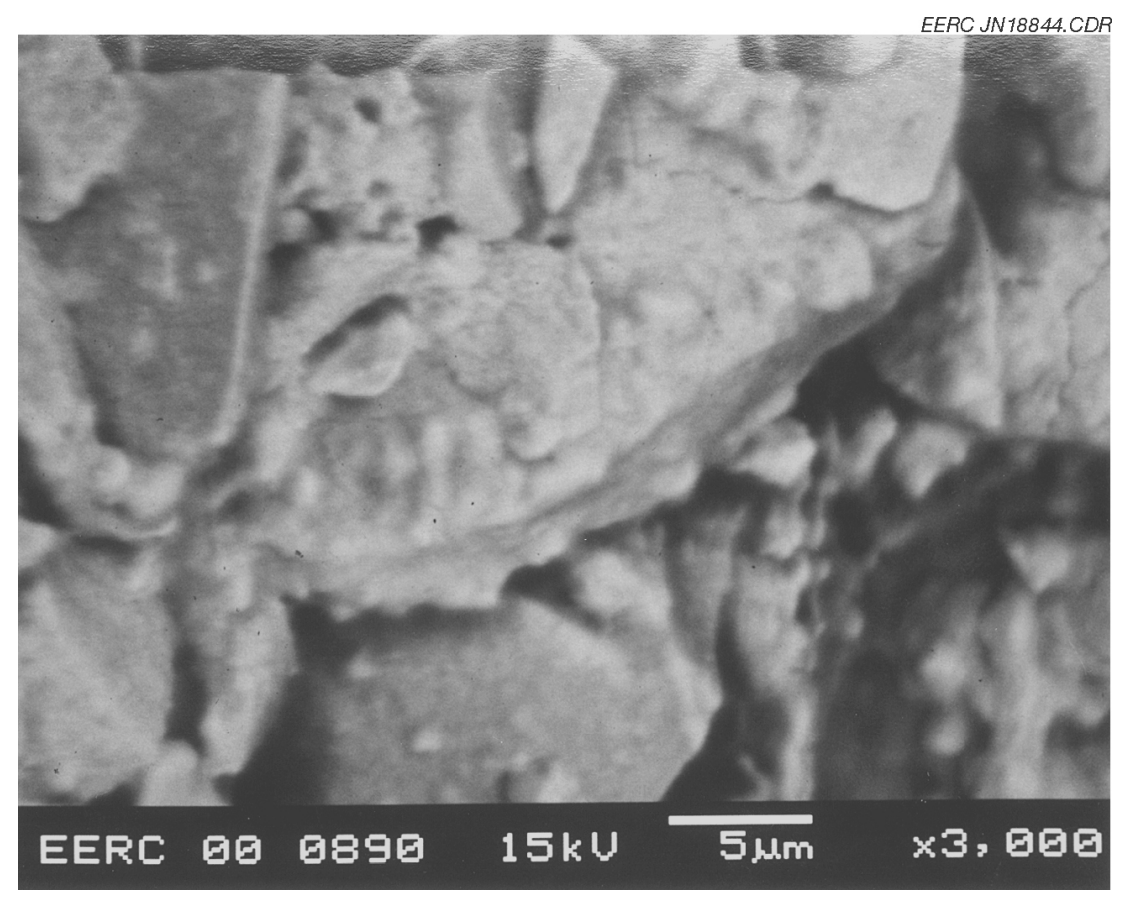

Figure 10. Surface of the silica-bonded $\mathrm{SiC}$ substrate after dipping once in $12 \%$ lithium formate and annealing at $700^{\circ} \mathrm{C}$.

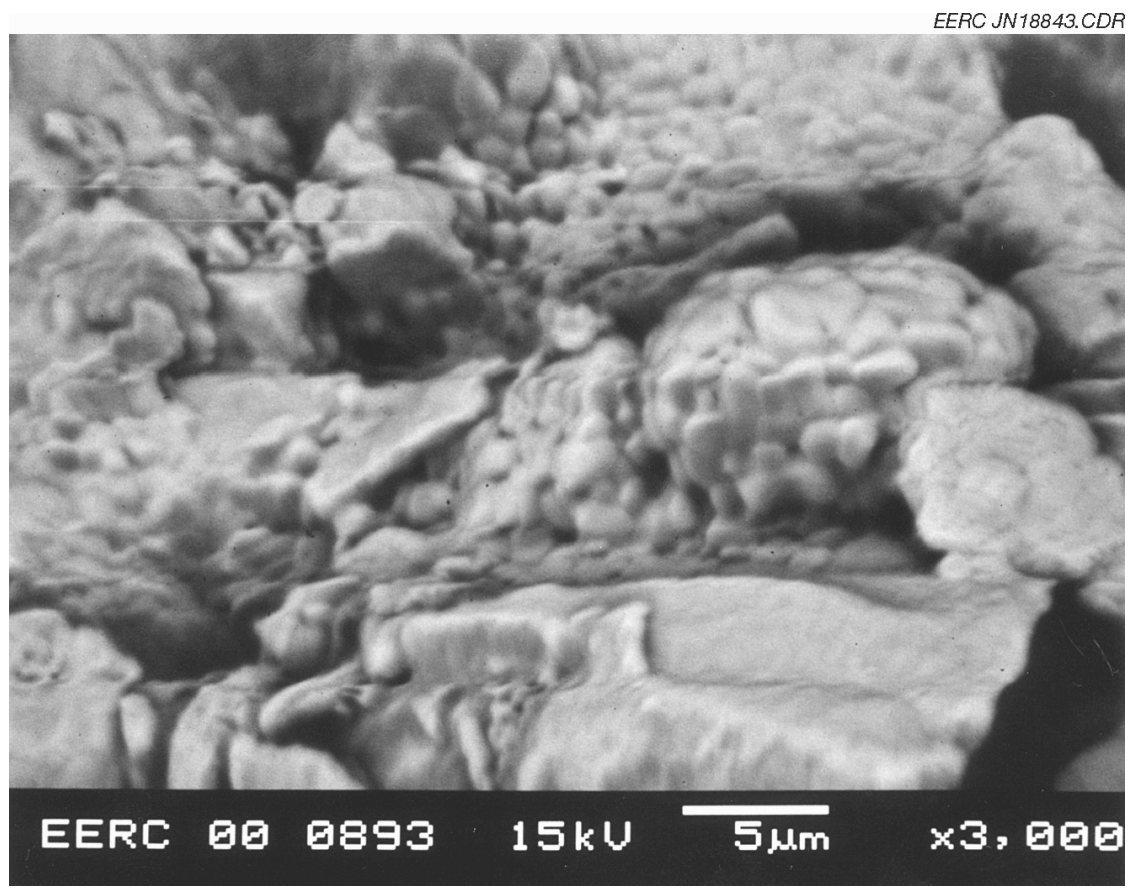

Figure 11. Surface of the silica-bonded SiC substrate after the second dip and anneal with $20 \%$ lithium formate. 


\section{SGD MECHANICAL DESIGN}

Both the combustion and gasification SGDs consist essentially of disks of coated porous ceramic sponge $3 \mathrm{in}$. in diameter and $1 \mathrm{in}$. thick. The disks are seal-welded in a metal cylinder to the hold-down plate used to seal the candle filters in the tube sheet. The disks are supported with coarse backup metal plates so that they can withstand high pressure drop periods such as a backpulse or candle filter failure at the full filter system pressure drop. This design is shown in Figure 12. It consists of the coated ceramic foam material inserted into a metal cylinder manufactured from 3-in. Schedule 40 pipe and sealed around the outside of the foam with either Interam intumescent mat material or with a compressed layer of glass fiber Koalwool. The foam SGD is also held in place with gaskets of Interam gasket material on the top of the upper coarse metal support disks. The Interam gasket material expands upon heating to ensure that the foam material will remain sealed in the metal cylinder even with the differences in the expansion coefficients between the metal cylinder and the ceramic foam.

\section{BENCH-SCALE TESTING}

In the Task 2 final report describing proposed Task 5 and optional bench-scale testing of the SGDs (4), the EERC described planned bench-scale tests of three types of combustion SGDs, the 80-ppi ZTA disks, the 60-ppi ZTA disks, and the PRD-66 cylinders, each coated with the Compound $B$ adhesive coating, and inclusion of one configuration of gasification SGD in the filter vessel of the EERC pilot-scale entrained-bed gasifier known as the transport reactor development unit (TRDU). However, during setup for the first combustion test with the 80-ppi SGDs, the disks were crushed by the tubes carrying the backpulse gas. Therefore, the first test was performed with the 60-ppi ZTA

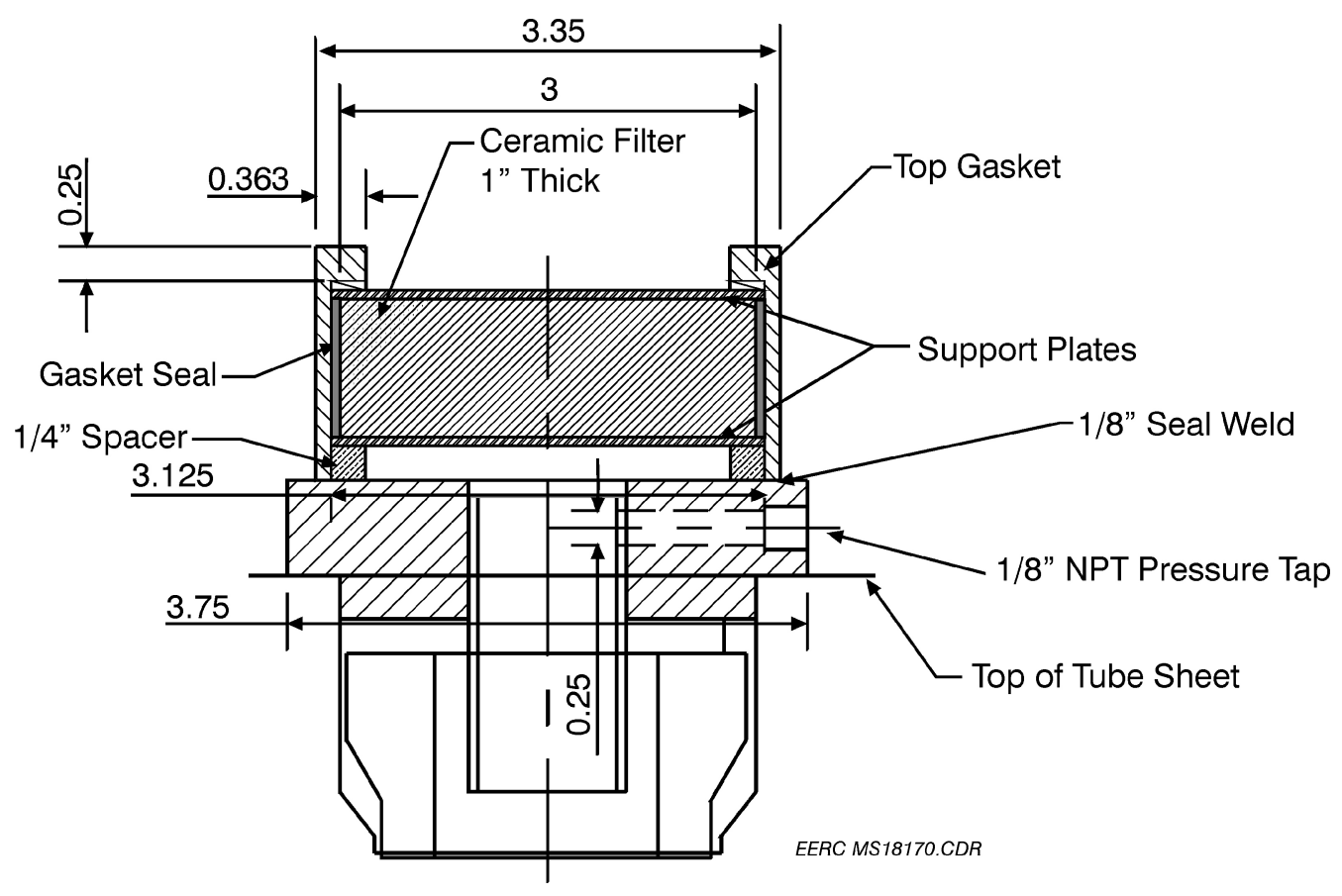

Figure 12. EERC SGD. 
disks. Given the weakness of the 80-ppi disks and the success of the 60-ppi disks (described in the following sections), the 80-ppi disks were dropped from testing and replaced with a test of 30-ppi ZTA disks. Also, because of the relatively high pressure drop of the PRD-66 cylinders and the fact that Honeywell Advanced Composites was not going to continue its production, they were also dropped from the tests. Instead, it was decided to test one configuration of the gasification SGD in a bench-scale bubbling bed coal gasification system under better-controlled conditions than could be produced in the TRDU.

\section{Combustion Testing}

\section{Description of the Bench-Scale Combustion Testing System}

The bench-scale tests of the combustion SGDs were performed in the pressurized fluidized-bed reactor (PFBR) which has been constructed to simulate the bed chemistry, ash interactions, and emissions from a PFB under closely controlled conditions. This reactor has been used for sorbent characterization, gaseous emissions including trace elements, agglomeration, and hot-gas cleanup testing in a cost-effective manner over a wide range of operational conditions. The conditions used during the SGD tests were very similar to those in the Siemens-Westinghouse particle filter being tested at the Southern Company Services PSDF while operating as a combustor. The typical range of operating conditions for the system are listed in Table 1.

A bench-scale filter vessel was used in conjunction with the PFBR to obtain high-temperature, high-pressure operational data on the SGDs. This vessel handles all of the gas flow from the PFBR at its nominal design conditions. It is shown in a schematic with the PFBR in Figure 13. The vessel has a 10-in. (25.4-cm) i.d. and is 60 in. $(152 \mathrm{~cm})$ long (including cone, vessel, and cap) and can handle a gas flow up to $30 \mathrm{scfm}(850 \mathrm{slpm})$ at $1550^{\circ} \mathrm{F}$ and $150 \mathrm{psig}(11 \mathrm{~atm})$. The tube sheet is interchangeable to handle different-sized filters or SGDs. The filters are currently sealed in an uncooled tube sheet with a bolted metal plate and Nextel fiber gaskets which counteract the upward force imparted across the candle filter by the filter's differential pressure. A schematic of the PFBR and filter vessel is shown in Figure 13.

Table 1. Typical PFBR Operating Conditions.

\begin{tabular}{lc} 
Reactor Diameter & 2.875 -in. $(7.303-\mathrm{cm})$ i.d. \\
Temperature & $1400^{\circ}-1700^{\circ} \mathrm{F}\left(760^{\circ}-930^{\circ} \mathrm{C}\right)$ \\
Pressure & $0-150 \mathrm{psig}(1-11 \mathrm{~atm})$ \\
Gas Flow Rate & $1-30 \mathrm{scfm}(28-850 \mathrm{slpm})$ \\
Coal Feed Rate & $1-8 \mathrm{lb} / \mathrm{hr}(0.5-3.6 \mathrm{~kg} / \mathrm{hr})$ \\
Velocity & $1-10 \mathrm{ft} / \mathrm{sec}(30-305 \mathrm{~cm} / \mathrm{sec})$ \\
Cyclone Exit Temperature & $1600^{\circ} \mathrm{F} \operatorname{maximum}\left(871^{\circ} \mathrm{C}\right)$ \\
Particulate Loading & $200-9000 \mathrm{ppm}$ \\
\hline
\end{tabular}




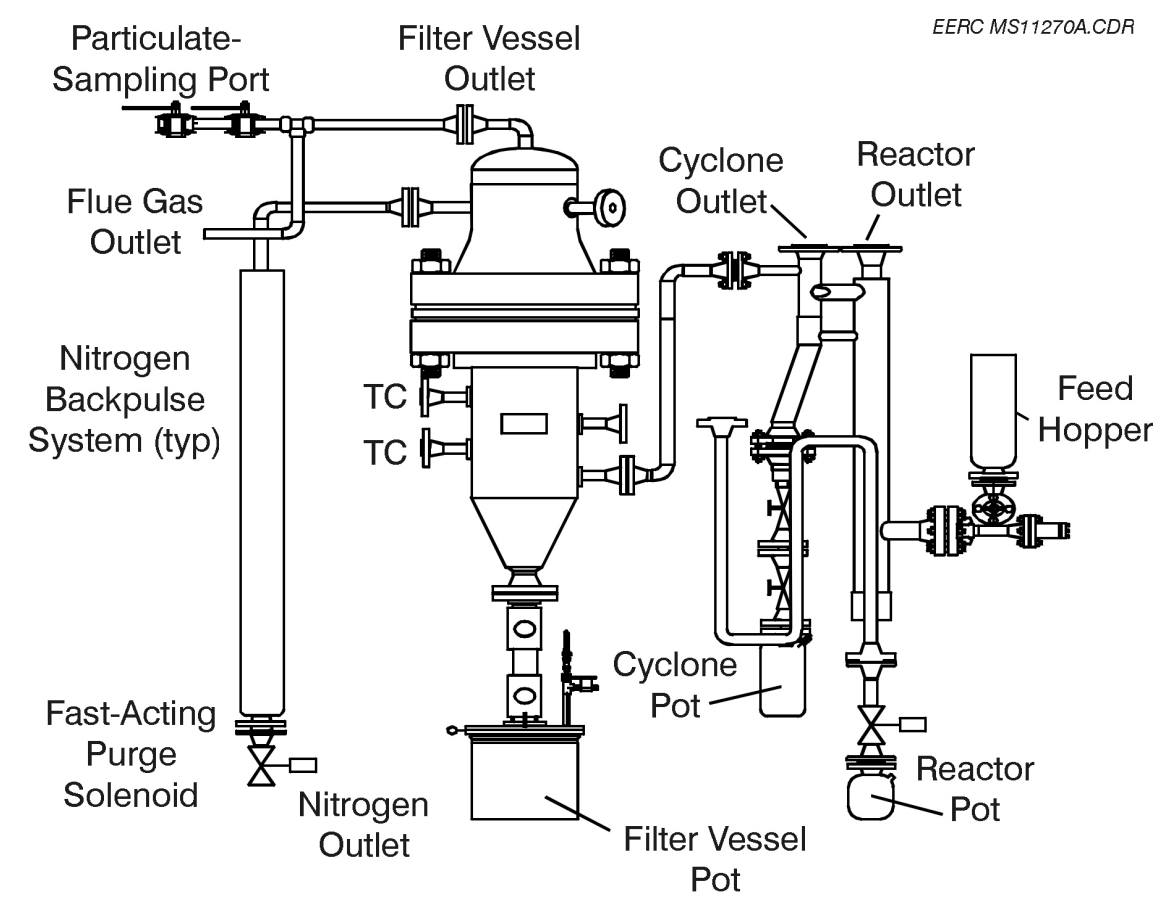

Figure 13. Schematic of the PFBR with the hot-gas filter vessel in place.

The uncooled tube sheet used in the filter vessel is illustrated in Figure 14. It is 2 in. $(5.1 \mathrm{~cm})$ thick, with three hemispherical openings for the candle filters, along with hold-down plates to seal the candle filters in place. Holes were drilled through the side of the tube sheet to allow pressure tap measurements between the candle filter and the SGD. Two additional differential pressure transmitters were added to the data acquisition and control system to permit measurements of pressure drops across both the candle filter and the SGD. The vessel is sized for three candle filters up to $18 \mathrm{in}$. $(46 \mathrm{~cm})$ long with a 2.375 -in. $(6.0325-\mathrm{cm})$ o.d. This provides candle space of 3.85 -in. $(9.78-\mathrm{cm})$ center line to center line and enables filter face velocities as low as $3 \mathrm{ft} / \mathrm{min}(1.5 \mathrm{~cm} / \mathrm{sec})$ to be tested in the PFBR. Higher face velocities can be achieved by using shorter or fewer candles or moderately higher gas flow rates, although plans are to use three candle filters. For the SGD testing, up to three 15 -in. $(38-\mathrm{cm})$ candle filters and SGDs were placed in the filter vessel. Operating conditions for the filter vessel are shown in Table 2. Ports in the filter vessel were used for temperature and pressure measurements.

The nitrogen backpulse system is designed to supply a minimum of three candle volumes per pulse. Room temperature backpulse nitrogen will be used in this program.

An Analog Devices ${ }^{\mathrm{TM}}$ data acquisition and control system using Iconics Genesis ${ }^{\mathrm{TM}}$ software was $^{2}$ used to monitor and record all critical pressures, temperatures, flow rates, and emissions. These critical data include the gas flow rates, bed static pressure and differential pressures across the bed and filter vessel, and eleven different internal reactor temperatures and six different hot-gas filter vessel temperatures. These data points are saved every 30 seconds. The data acquisition software was modified to acquire important transient pressure information such as differential pressure across the 
Table 2. High-Temperature, High-Pressure Bench-Scale Filter Vessel Operating Capabilities.

Vessel Diameter 10-in. $(25.4-\mathrm{cm})$ i.d.

Temperature $\quad 1450^{\circ} \mathrm{F}\left(788^{\circ} \mathrm{C}\right)$

Pressure $\quad 150 \mathrm{psig}(11.2 \mathrm{~atm})$

Gas Flow Rate Up to $30 \mathrm{scfm}(850 \mathrm{slpm})$

Filter Size $\quad 2.375-$ in. $(6.03-\mathrm{cm})$ o.d. by 15 in. $(38.1 \mathrm{~cm})$ long

Filter Face Velocity $4 \mathrm{ft} / \mathrm{min}(2 \mathrm{~cm} / \mathrm{sec})$

$\mathrm{N}_{2}$ Backpulse System Room temperature with either short, high-pressure or long, low-pressure pulses

candle filter and SGD at 1-second intervals during backpulsing. The air and nitrogen flow rates were controlled automatically to flow rate set points. The reactor pressure was automatically controlled to a pressure set point. Continuous emissions sampling of the flue gas measures the levels of $\mathrm{O}_{2}$, $\mathrm{SO}_{2}, \mathrm{NO}_{x}, \mathrm{~N}_{2} \mathrm{O}, \mathrm{CO}, \mathrm{CO}_{2}$, and hydrocarbon. Solid samples collected included bottom ash, fly ash, and particulate samples from the stack to determine the particulate loading leaving the filter vessel.

\section{PFBR Test Procedures}

The following was the nominal plan used for the combustion tests. Some variations occurred because of unforseen operating issues. Three different parameters of SGD performance were measured over each 2-day test. The first parameter was unactivated pressure drop. This was

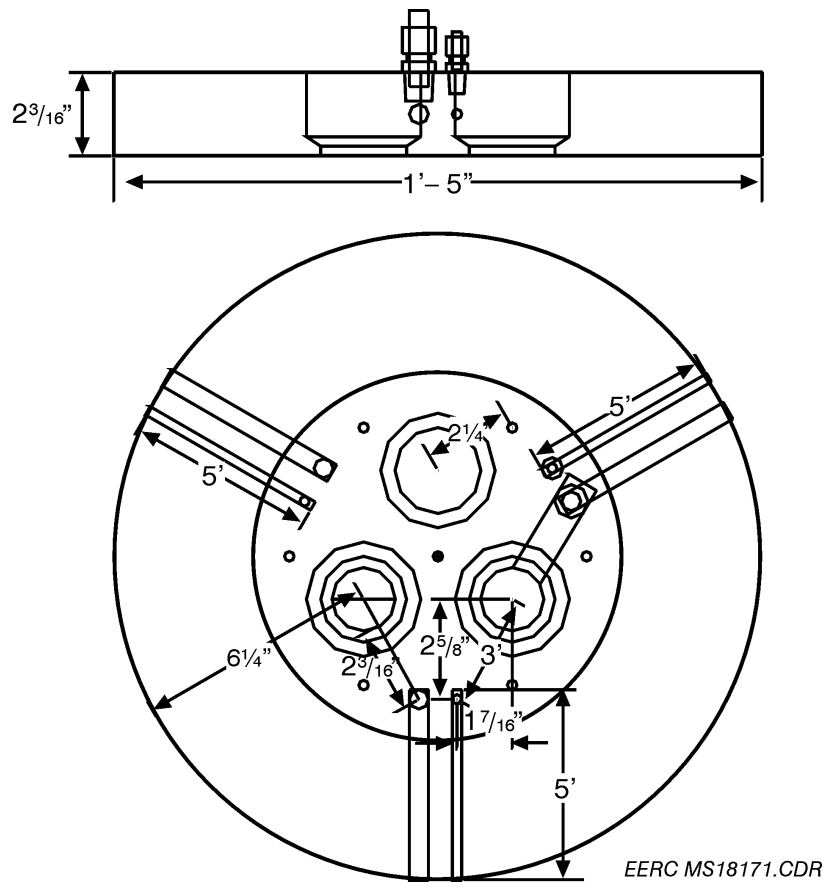

Figure 14. Existing EERC tube sheet with backpulse and pressure tap nozzles. 
determined by measuring the pressure drops across each candle filter and the SGD on top of each filter at ambient temperatures and face velocities of 4, 7, and $10 \mathrm{ft} / \mathrm{min}(2.0,3.6$, and $5.1 \mathrm{~cm} / \mathrm{sec})$. This test was then repeated at system temperatures of $1000^{\circ}\left(538^{\circ} \mathrm{C}\right)$ and $1400^{\circ} \mathrm{F}\left(760^{\circ} \mathrm{C}\right)$. The second measurement was used to demonstrate under actual coal combustion conditions the SGD operability under the inactive mode of operation. During this phase of the test, the system was to nominally run continuously for 24 hours. The following parameters were monitored during this portion of the test:

- Pressures in the dirty gas inlet and clean gas plenum and the differential pressure across the tube sheet and in the cavity between two filters and its associated SGD

- The transient pulse pressures in the cavities

- Backpulse gas operating conditions and gas consumption

- Interval between backpulses

- Outlet dust loadings, collected using U.S. Environmental Protection Agency (EPA) Method 5

Operation was nominally conducted with the following backpulse conditions:

- One pulse of room temperature nitrogen per candle, nominally a 500-ms duration.

- Pulse pressures in the cavities of up to 3 psi (155 $\mathrm{mmHg})$ above inlet (dirty gas) pressure.

- Initiation of backpulse when the candle filter reaches the preselected level of a 30-minute time interval, although shorter periods would be selected if the filter differential pressure increased more than 3 psid.

The third portion of each 2-day baseline test was to demonstrate the effectiveness of the SGD when a candle filter fails. Following the completion of the unactivated test, a drill bit welded on a stainless steel shaft was inserted through a thermocouple port, specifically modified to accommodate it, during operation to break or drill a hole in one of the candle filters. This allowed the SGD above the candle to be activated while in operation with the other filter(s) handling the increased load once the SGD plugged. The pressure drop across the filter as a function of time and the time required to plug the filter were measured. The system was run through several pulse cycles over an 8-hour period to demonstrate the ability of the SGD to retain a permanent dust seal. In addition to the pressure drop data, several EPA Method 5 particulate tests were conducted to characterize the particle-size loading and distributions at the outlet of the filter/SGD as a function of time. The results from each test included a fractional collection efficiency curve, pressure drop across the SGD as a function of time, and mass of dust that passes through the filter/SGD. 


\section{Combustion Test Results}

\section{Test 1 - 60-ppi SGD}

The first set of SGDs, designated F, G, and H, was tested in December 2000. Figure 15 shows a closeup of the SGDs in place on the tube sheet of the hot-gas filter vessel. While the test should have been completed in about 48 continuous hours, operating difficulties resulted in the tests being conducted over four periods, with shutdowns in between. EERC personnel believe that the thermal and pressure cycling had no adverse effect on the performance of the candle filters or SGDs.

Baseline testing was conducted on December 13 at several temperatures (ambient, $900^{\circ} \mathrm{F}$ $\left[482^{\circ} \mathrm{C}\right]$, and $1300^{\circ} \mathrm{F}\left[704^{\circ} \mathrm{C}\right]$ ) and pressures prior to coal feed. The data are shown in Table 3 . Face velocities of 4, 7, and $10 \mathrm{ft} / \mathrm{min}(2.0,3.6$, and $5.1 \mathrm{~cm} / \mathrm{s})$ were used when possible, although for the tests at operating pressure, the maximum face velocity was limited to $7.5 \mathrm{ft} / \mathrm{min}(3.8 \mathrm{~cm} / \mathrm{s})$ because of the small piping through the backpressure valve. The SGD differential pressure ranged from 0.4 to 1.6 in. $\mathrm{H}_{2} \mathrm{O}(0.7-3.0 \mathrm{mmHg})$, depending on face velocity. The differential pressure across each of the three SGDs was very consistent, virtually indistinguishable when placed on the same graph.

Coal feed was initiated at the completion of the baseline tests. While the overall filter vessel differential pressure increased steadily, there was no increase in differential pressure across any of the SGDs. Backpulsing the candle filters had no apparent effect on the performance of the SGDs. Difficulties with both the data acquisition system and the filter vessel backpulse system forced a

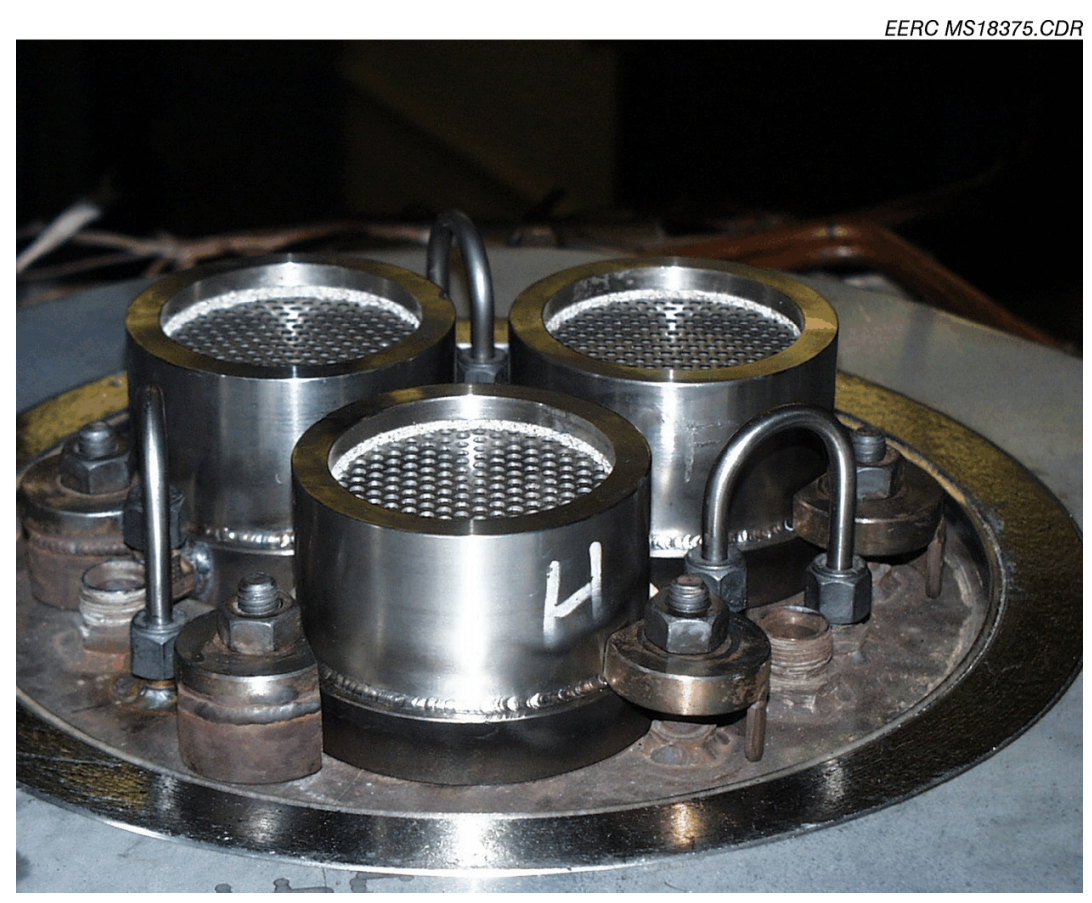

Figure 15. Closeup of the combustion SGDs in place on top of the tube sheet in the hot-gas filter vessel. 
Table 3. Baseline PFBR Test Data for the 60-ppi SGD ${ }^{1}$.

\begin{tabular}{lcccc}
\hline Temperature, ${ }^{\circ} \mathrm{F}\left({ }^{\circ} \mathrm{C}\right)$ & $\begin{array}{c}\text { Face Velocity, } \\
\mathrm{ft} / \mathrm{min}(\mathrm{cm} / \mathrm{sec})\end{array}$ & $\begin{array}{c}\text { Static Pressure, } \\
\mathrm{psia}(\mathrm{atm})\end{array}$ & $\begin{array}{c}\text { Filter Vessel dP } \\
\text { in } \mathrm{H}_{2} \mathrm{O}(\mathrm{mmHg})\end{array}$ & $\begin{array}{c}\text { SGD dP } \\
\text { in } \mathrm{H}_{2} \mathrm{O}(\mathrm{mmHg})\end{array}$ \\
\hline $80(27)$ & $3.9(2.0)$ & $9(1.6)$ & $1.5(2.8)$ & $0.5(1.0)$ \\
$80(27)$ & $6.0(3.5)$ & $15(2.0)$ & $2.3(4.3)$ & $0.8(1.4)$ \\
$80(27)$ & $9.9(5.0)$ & $28(2.9)$ & $2.5(4.7)$ & $0.9(1.7)$ \\
$900(482)$ & $4.2(2.1)$ & $29(30)$ & $3.3(6.2)$ & $0.7(1.4)$ \\
$900(482)$ & $7.0(3.6)$ & $45(4.1)$ & $7.0(13.1)$ & $1.3(2.4)$ \\
$900(482)$ & $7.5(3.8)$ & $39(3.7)$ & $7.5(14.0)$ & $1.5(2.8)$ \\
\hline
\end{tabular}

1 “Clean” tests of safeguard devices, December 13, 2000.

shutdown after 4.1 hours of operation. The system was depressurized and cooled while repairs were made to the data acquisition system.

The second day of coal firing lasted just over 20 hours, starting on December 18 . The data are shown in Figure 16. Just as personnel were preparing to break the first candle filter, the bed agglomerated, forcing a second shutdown. During that time, the SGDs continued to perform as expected, maintaining a consistent differential pressure of about $1.4 \mathrm{in} . \mathrm{H}_{2} \mathrm{O}(2.6 \mathrm{mmHg})$, even as the filter vessel differential pressure rose from 5 to $15 \mathrm{in}$. $\mathrm{H}_{2} \mathrm{O}$ (9.3 to $\left.28.0 \mathrm{mmHg}\right)$. The $\mathrm{H}$ SGD read slightly lower than the other two. The filter vessel inlet temperature was $1500^{\circ} \mathrm{F}\left(816^{\circ} \mathrm{C}\right)$, and the temperature near the candles was about $1420^{\circ} \mathrm{F}\left(771^{\circ} \mathrm{C}\right)$.

An hour after initiating coal firing on the third day, December 21, the first candle filter, associated with SGD G, was broken on-line. The flow rate and pressure data are shown in Figure 17. In order to break the filter, a drill bit was installed in a flange in the side of the filter vessel at the time the candles were installed. Initially, a drill was used to rotate the bit in an attempt to make a hole in the candle filter. However, the filter proved too hard to drill into, so the bit was hammered into the filter until it broke. The differential pressure across the filter vessel dropped immediately as the candle was broken, but climbed back to the original level within 5 minutes and continued climbing as the SGD was rapidly plugging with filter dust. The differential pressure across SGD G was about 1.2 in. $\mathrm{H}_{2} \mathrm{O}(2.2 \mathrm{mmHg})$ before the candle was broken, but in 5 minutes it had risen to 10 in. $\mathrm{H}_{2} \mathrm{O}(18.7 \mathrm{mmHg})$. The $\mathrm{SGD}$ differential pressure continued to measure about 3 in. $\mathrm{H}_{2} \mathrm{O}$ (5.6 $\mathrm{mmHg}$ ) higher than the filter vessel differential pressure for the remainder of the test period (about 4 hours). About 40 minutes after the candle was broken, the filter vessel differential pressure had reached 15 in. $\mathrm{H}_{2} \mathrm{O}(381 \mathrm{mmHg})$, reflecting the increase in face velocity from about $3.3 \mathrm{ft} / \mathrm{min}$ $(1.7 \mathrm{~cm} / \mathrm{s})$ to about $5 \mathrm{ft} / \mathrm{min}(2.5 \mathrm{~cm} / \mathrm{s})$. At this point, the first backpulse was initiated. The filter vessel differential pressure displayed a "sawtooth" pattern every 30 minutes, varying 3 in. $\mathrm{H}_{2} \mathrm{O}$ $(5.6 \mathrm{mmHg})$ with each backpulse sequence. Gradually, the baseline differential pressure (that 


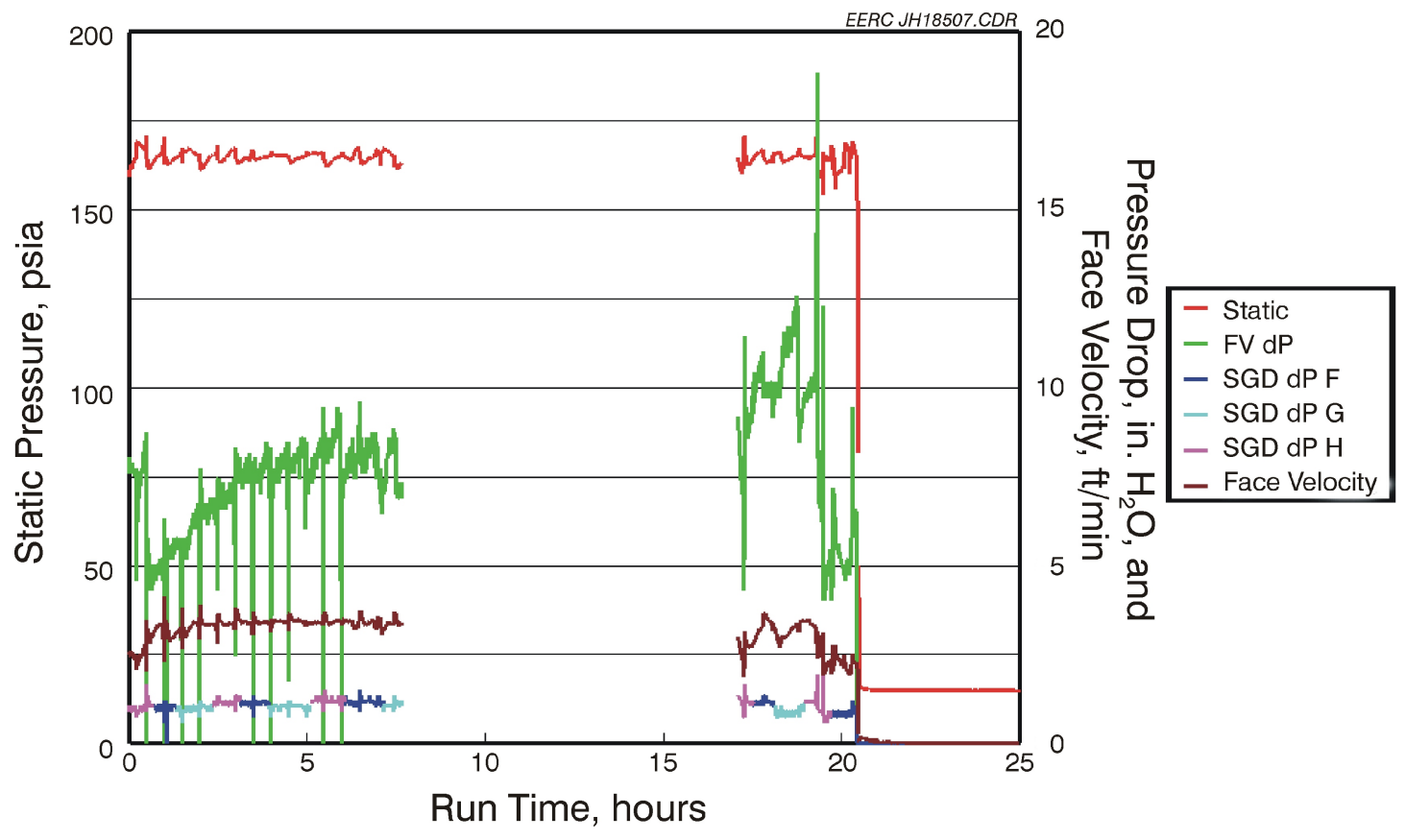

Figure 16. PFBR test data from December 18 during the steady-state operation before any candle filters were broken.

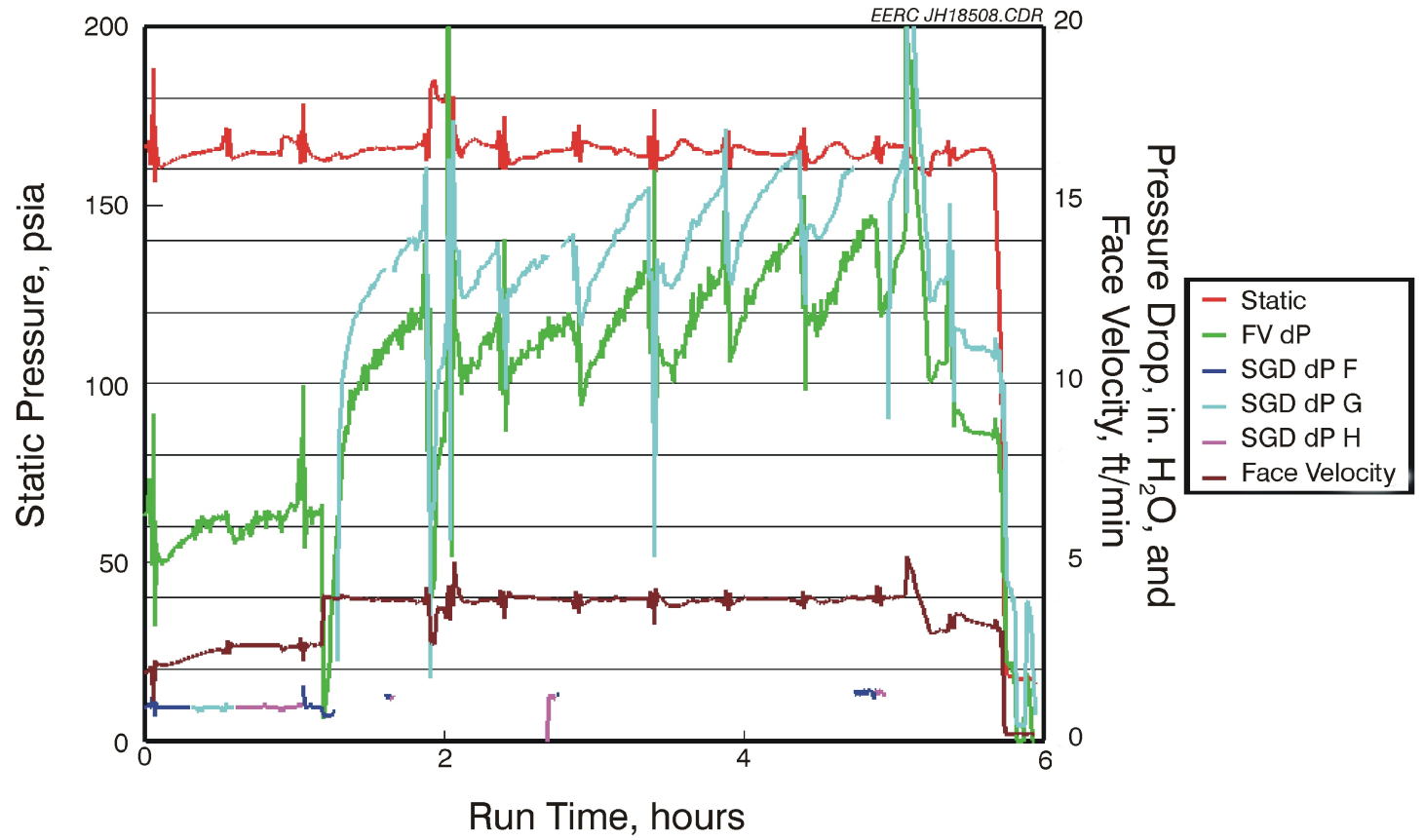

Figure 17. PFBR test data from December 21 after the first candle filter was broken. 
measured after backpulsing) across the filter vessel reached 15 in. $\mathrm{H}_{2} \mathrm{O}(28.0 \mathrm{mmHg})$. The filter vessel inlet temperature was $1500^{\circ} \mathrm{F}\left(816^{\circ} \mathrm{C}\right)$, and the temperature near the candles was about $1450^{\circ} \mathrm{F}$ $\left(788^{\circ} \mathrm{C}\right)$.

Over the course of the day, the pressure transmitter was switched to SGDs F and H to verify that they were handling the increase in flow. After the first candle was broken, the differential pressure across SGDs F and $\mathrm{H}$ increased slightly, from about 1.2 in $\mathrm{H}_{2} \mathrm{O}(2.2 \mathrm{mmHg})$ to about 1.7 in $\mathrm{H}_{2} \mathrm{O}(3.2 \mathrm{mmHg})$, as the gas flow through them increased because of the plugging of SGD G. Approximately 4 hours after the candle filter was broken, the reactor cyclone plugged, forcing yet another shutdown. It was determined at that time that the fuel being used had a much higher ash content than what was expected. Before completing the final portion of the test, a lower-ash coal was obtained. This coal will be used for all subsequent test runs.

The final segment of the test took place December 26 (Figure 18). Coal feed was initiated and the reactor brought up to temperature and pressure. Because of the orientation of the candle filters relative to the flange, the second candle could not be broken on-line. Coal feed and fluidizing gas flows were stopped after 3 hours and 50 minutes, and the reactor depressurized to allow personnel to remove the flange and break the second candle associated with SGD F. Coal feed was off for 48 minutes. Filter vessel inlet temperature was $1500^{\circ} \mathrm{F}\left(816^{\circ} \mathrm{C}\right)$, and the temperature near the candles was about $1430^{\circ} \mathrm{F}\left(777^{\circ} \mathrm{C}\right)$ when the system reached equilibrium after restarting coal feed. As occurred for the first test, the differential pressure across the remaining filter and across the SGD increased rapidly as coal feed was reinitiated, indicating a rapid plugging of the SGD above the broken candle. This rapid plugging demonstrates the reproducibility in the performance of the SGDs. System operation with backpulse cleaning was continued for 8 hours after breaking the second candle to determine if the plugged SGDs would be cleaned at some point because of the backpulses.

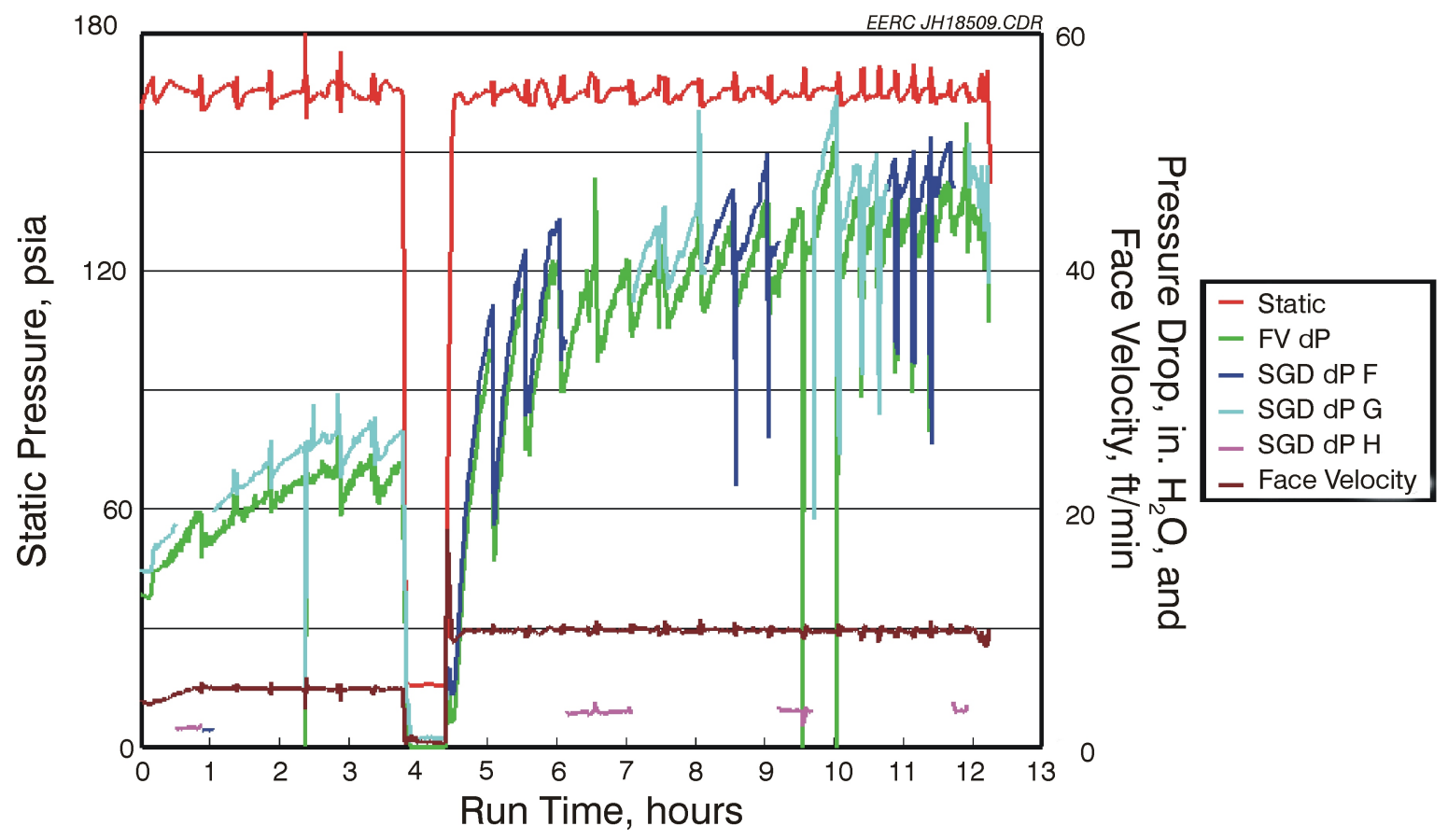

Figure 18. PFBR test data from December 26 after the second candle filter was broken. 
The differential pressure continued to show the sawtooth pattern, indicating the SGDs were irreversibly plugged.

During the bench-scale test, a series of dust loading measurements were performed to determine the ability of the SGD to prevent passage of particulate matter after a candle filter breaks. A modified EPA Method 5d (5) sample train was used. Modifications to the Method 5 train included the use of a 2.5 -in. $(6.35-\mathrm{cm})$ stainless steel pressurized filter holder operated at $150 \mathrm{psi}(11.2 \mathrm{~atm})$ and $400^{\circ} \mathrm{F}\left(204^{\circ} \mathrm{C}\right)$. Since the system was at pressure, the sample pump was eliminated and a needle valve substituted on the outlet side of the filter to control flow rates. A series of impingers was used to collect moisture, and a dry gas meter was used to measure the total gas volume sampled. Average dust loading calculations are expressed as ppm (mass dust/mass gas * 1,000,000).

Results and explanations are listed below:

Sample 1 (167 ppm)

Sample 2(21 ppm)

Sample $3(56 \mathrm{ppm})$

Sample 4 (17 ppm)

Sample $5(10 \mathrm{ppm})$

Sample $6(18 \mathrm{ppm})$
During coal firing but before breaking a candle filter, 22 minutes of sampling time. Computer malfunction caused system upset and a switch to reducing conditions, filter was black with carbon and/or organic compounds, possibly from system contamination or vaporized antiseize compounds.

Baseline, no broken candles, visible ash on filter, dust loading probably still being affected by system upset or the dust cake on the candles may still be coming to equilibrium (we have seen lower dust loadings for well-seasoned candles).

Sample started immediately after breaking the first candle on December 21. Sample collected for 30 minutes.

Sample started approximately 2 hours after Sample 3 (one broken candle). Collected Sample for 60 minutes.

December 26, this test was to verify SGD performance prior to breaking the second candle. Sample collected for 60 minutes for better accuracy. After the test, a light green residue was noticed on the filter and filter holder; the material appears to be some vapor-phase compound that deposited as it cooled from the stack temperature of $800^{\circ} \mathrm{F}\left(427^{\circ} \mathrm{C}\right)$ to the filter temperature of $400^{\circ} \mathrm{F}\left(204^{\circ} \mathrm{C}\right)$. Future runs will have heat tape installed on exposed sample lines and valves; in addition, the filter temperature will be increased to $450^{\circ} \mathrm{F}$ $\left(232^{\circ} \mathrm{C}\right)$.

Sample started immediately after breaking the second candle while off-line and system had been repressurized to steadystate operating condition. Sample collected for 60 minutes. 

Sample 6 (two broken candles). Collected for 60 minutes.

Overall, the results of the bench-scale tests of the 60-ppi combustion SGD were excellent, showing plugging of the SGD within a few minutes of the breakage of a candle filter. In addition, the activated SGDs were not damaged by backpulse cleaning, different SGDs had reproducible behaviors, and they irreversibly plugged. Also, particulate concentrations in the gas downstream of the SGDs generally did not increase because of breakage of a candle filter, implying that the SGDs were very efficient at capturing the particles passing through the broken candle. However, overall particulate loadings were higher than is desirable, even before breaking the candle filter. The relatively high loadings implied a possible leak of particulates around the candle filters and SGDs. Therefore, the particulate filters were analyzed by SEM. The analyses showed that almost all of the weight gain on the particulate-sampling filters was due to condensation of acid gases and iron sulfate that were in the vapor phase at the temperatures of the candles and SGDs. No ash particulates were seen on the surfaces of the sampling filters at all. Figure 19 is an SEM photograph of the surface of the EPA Method 5 particle filter. The rounded particle on the upper left is a droplet of condensed sulfuric acid, whereas the irregular particle is an agglomerate of condensed iron sulfate particles.

In order to determine the depth of penetration into and characteristics of the dust plugging of the SGDs, the second one activated was infiltrated with cyanoacrylate vapor (Super Glue) to lightly fix the trapped ash within the SGD. The structure was then slowly infiltrated with liquid epoxy. After polymerization, the SGD was cross-sectioned and polished. Figure 20 is a photograph of a polished cross section of the SGD. Gas flow would have been from the top in this picture. It shows that the red ash had penetrated densely approximately one-third of the way into the porous ceramic before

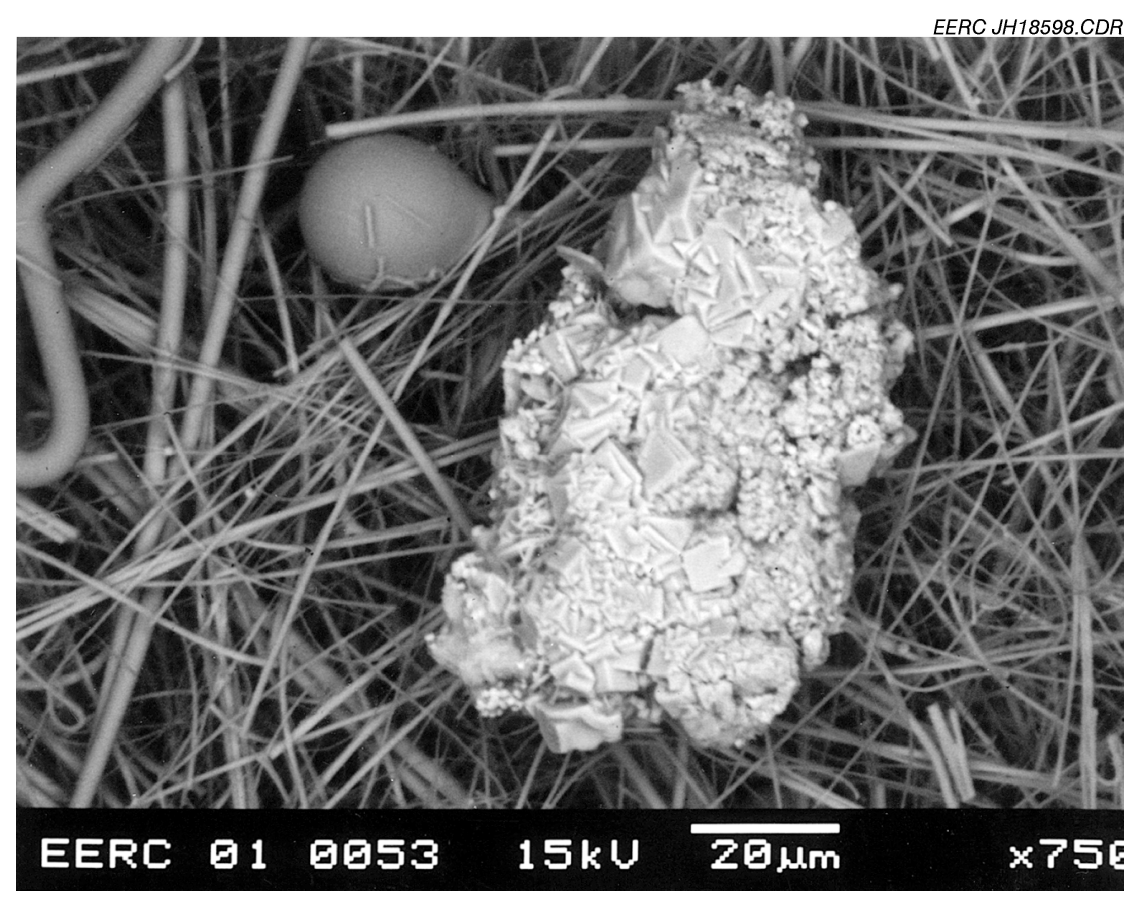

Figure 19. SEM photograph of the surface of the EPA Method 5 particle filter from the test of the 60-ppi combustion SGD. 


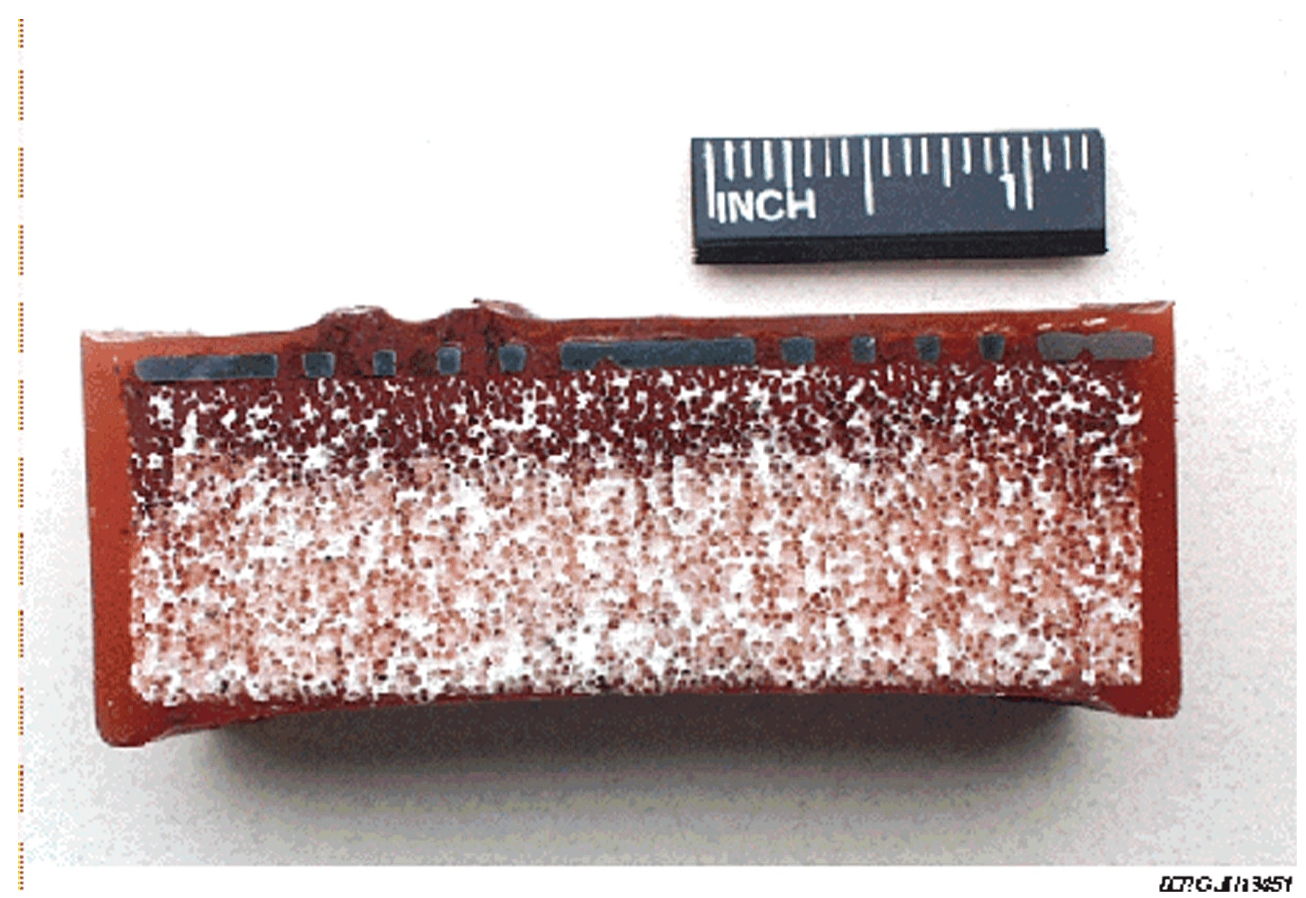

Figure 20. Cross section of one of the combustion SGDs tested in December 2000.

the SGD was plugged. There were light bands of ash that penetrated somewhat further, but the light pink material below the dense red layer contains very little ash that was most likely carried into the SGD by the epoxy. This depth of penetration indicates that a 1-in. $(2.5-\mathrm{cm})$-thick ceramic substrate is the appropriate thickness.

Figure 21 shows a SEM photograph of a pore containing ash in the densely filled section of the exposed SGD. The SGD ceramic is ZTA. Within the porous ceramic structure, the zirconia appears as 1- to 5-micron-diameter blobs in the darker gray alumina matrix. The black area is the epoxy-filled pore. The larger, light gray blobs near the bottoms of the insides of the pores are primarily the Compound B sticky coating material which has either floated off into the epoxy or is present as blobs of material supported in a light gauze made of the compound, which is not obvious. The much smaller particles suspended in the epoxy in the main body of the pore are ash particles composed primarily of aluminosilicates derived from clay particles in the coal. They are typically only a few microns in diameter.

Our original assumption in the design of the SGD and the adhesive coating was that a few larger dolomite sorbent particles would be carried into the SGD as the candle was broken, and they would be stuck within the pores by the adhesive. In fact, very few sorbent particles were observed within the substrate, and none of them were even close to being large enough to block the passages between the pores. The lack of larger sorbent particles seen in cross section most likely occurs because the larger particles tend to settle out in the filter vessel and so do not reach the SGD. Because they are so few, the probability of cross-sectioning one during sample preparation is very 


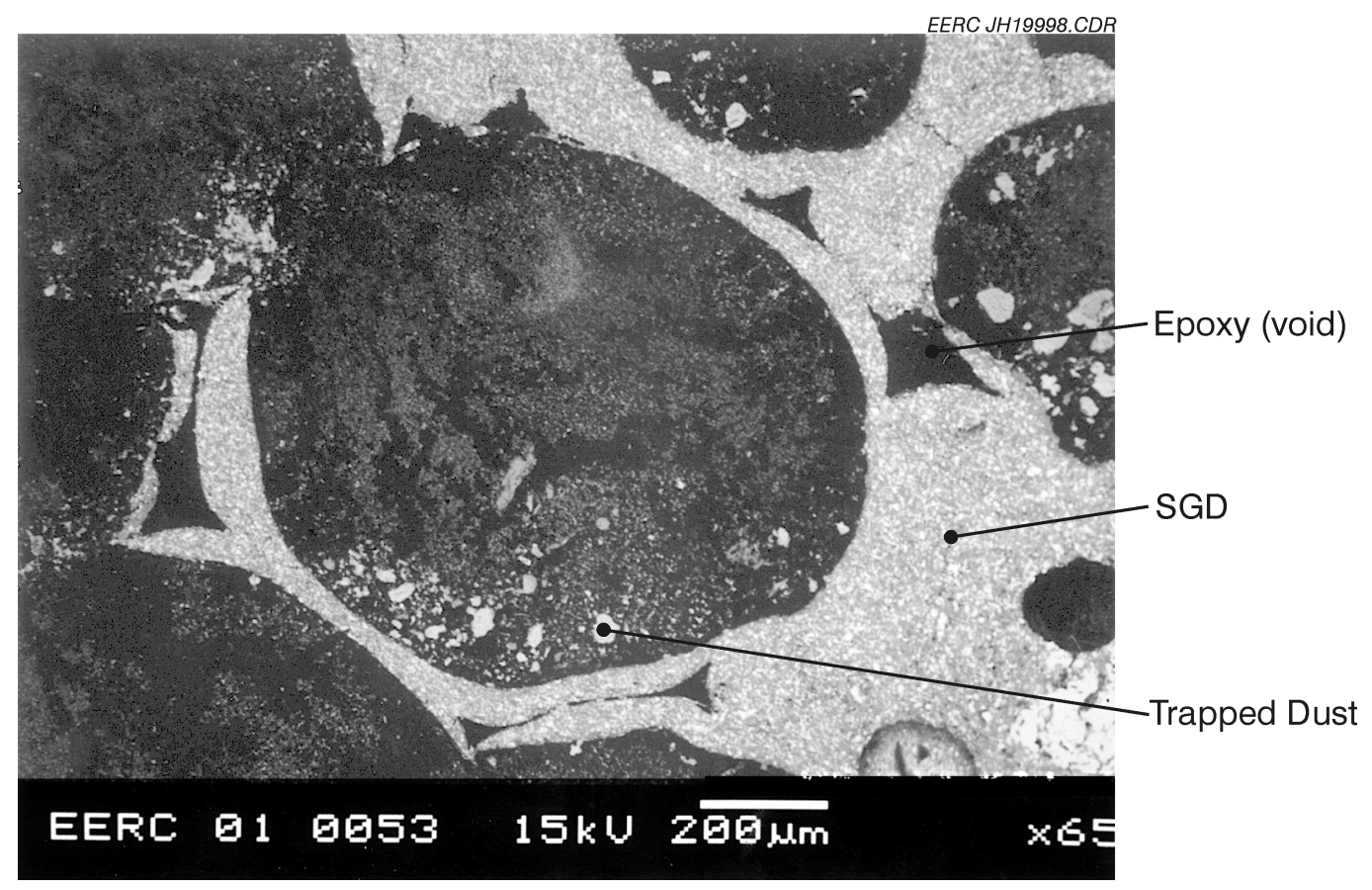

Figure 21. SEM photograph of a pore containing ash in the densely filled section of the exposed SGD.

low. However, it also indicates that plugging did not occur by a few large particles. Instead, it appears that the low-viscosity adhesive coating material lightly coats the particles entering the pores and causes them to agglomerate. Apparently the adhesive coats the silicate-based particles better than anticipated from macroscopic work with droplets of sulfate on silica slag beads. The agglomeration force is very low, but it is apparently sufficient to hold the particles together against a high-pressure backpulse of nitrogen. Also, the amount of adhesive coating on an individual particle is so low that it cannot be detected by SEM.

\section{0-ppi SGD}

Even though the PFBR test of the 60-ppi combustion SGD was very successful, it is advantageous to use a device with the lowest pressure drop possible. Also, at the time it was believed that we could only purchase 30-ppi SiC disks for the gasfication SGD, and we needed to know if the larger pores of a 30-ppi disk could plug rapidly if coated with an adhesive known to be effective (Compound B). Therefore, in February 2001, a second bench-scale combustion test was performed with the PFBR and hot-gas filter vessel, this time on a 30-ppi ZTA combustion SGD.

The SGDs used in the February test were designated 1, 2, and 3. The lower-ash coal, used for the final hours of the first test, was used for this test. One differential pressure transmitter was dedicated to recording the differential pressure across the filter vessel; another was plumbed to a 3-way valve to measure the differential pressure across a specific SGD. During operation, the valve was switched frequently to ensure data collection on all the SGDs. 
Baseline testing was conducted on February 20, 2001, at several temperatures (ambient, $900^{\circ} \mathrm{F}$, and $1300^{\circ} \mathrm{F}\left[480^{\circ} \mathrm{C}\right.$ and $\left.700^{\circ} \mathrm{C}\right]$ ) and pressures prior to initiating coal feed and at face velocities of 4,7 , and $10 \mathrm{ft} / \mathrm{min}(2.0,3.6,5.1 \mathrm{~cm} / \mathrm{sec})$ (when possible). The data are shown in Table 4. During all baseline tests, the differential pressure across the SGDs increased slightly with face velocity, as did the total face velocity differential pressure. The SGD differential pressure ranged from 0.6 to 1.6 in. $\mathrm{H}_{2} \mathrm{O}$ (1.1 to $3.0 \mathrm{mmHg}$ ) for the baseline tests, increasing at higher face velocity. At higher temperatures, more flow was required to achieve a given face velocity. Because of the relatively small pipe size through the backpressure valve, at the highest temperature the upper face velocity was limited to $7.4 \mathrm{ft} / \mathrm{min}(3.8 \mathrm{~cm} / \mathrm{sec})$. Figure 22 shows the filter vessel static pressure, differential pressures, and candle filter face velocity for the baseline tests.

Coal firing was initiated February 21. While the overall filter vessel differential pressure increased steadily to about 14 in. $\mathrm{H}_{2} \mathrm{O}(26 \mathrm{mmHg})$, there was no increase in differential pressure across any of the SGDs, showing that like the 60-ppi SGDs, they were not prone to premature plugging. Backpulsing the candle filters had no apparent effect on the performance of the SGDs. The filter vessel inlet temperature was $1475^{\circ} \mathrm{F}\left(802^{\circ} \mathrm{C}\right)$, and the temperature near the candles was about $1430^{\circ} \mathrm{F}\left(777^{\circ} \mathrm{C}\right)$.

Approximately 26 hours after initiating coal firing, the candle filter associated with SGD 1 was broken on-line. This time corresponds to run hour 26.5 in Figure 23 which shows the differential pressures and filter face velocity while firing coal. The data indicate that the filter vessel differential pressure transmitter experienced a zero shift, since the filter vessel differential pressure actually read 3 or 4 in. lower than the SGD differential pressure. The filter was broken by drilling into it with a drill bit that was installed in a flange in the side of the filter vessel at the time the candles were installed. With this design, the candle was broken while the system was at pressure.

The differential pressure across the filter vessel dropped from 12 to 0 in. $\mathrm{H}_{2} \mathrm{O}(22.4$ to $0 \mathrm{mmHg}$ ) when the candle broke. After 10 minutes, it began a steady increase, indicating that SGD 1 was beginning to plug. The SGD took approximately 1 hour to reach a differential pressure of

Table 4. Baseline PFBR Test Data for the 30 ppi SGD ${ }^{1}$.

\begin{tabular}{lcccc}
\hline Temperature, ${ }^{\circ} \mathrm{F}\left({ }^{\circ} \mathrm{C}\right)$ & $\begin{array}{c}\text { Face Velocity, } \\
\mathrm{ft} / \mathrm{min}(\mathrm{cm} / \mathrm{sec})\end{array}$ & $\begin{array}{c}\text { Static Pressure, } \\
\text { psia }(\mathrm{atm})\end{array}$ & $\begin{array}{c}\text { Filter Vessel dP } \\
\text { in } \mathrm{H}_{2} \mathrm{O}(\mathrm{mmHg})\end{array}$ & $\begin{array}{c}\text { SGD dP } \\
\text { in } \mathrm{H}_{2} \mathrm{O}(\mathrm{mmHg})\end{array}$ \\
\hline $81(27)$ & $4.0(2.0)$ & $14(1.0)$ & $1.1(2.1)$ & $0.7(1.3)$ \\
$81(27)$ & $6.8(3.5)$ & $15(1.0)$ & $2.7(5.0)$ & $1.0(1.8)$ \\
$81(27)$ & $9.3(4.7)$ & $15(1.1)$ & $4.6(8.5)$ & $1.5(2.8)$ \\
$854(457)$ & $4.5(2.3)$ & $24(1.7)$ & $1.7(3.2)$ & $0.7(1.3)$ \\
$1290(699)$ & $7.2(3.7)$ & $26(1.8)$ & $4.7(8.8)$ & $0.9(1.7)$ \\
$1335(724)$ & $7.4(3.8)$ & $31(2.1)$ & $5.3(9.9)$ & $1.0(1.9)$ \\
\hline
\end{tabular}

1 "Clean" tests of safeguard devices, February 20, 2001. 


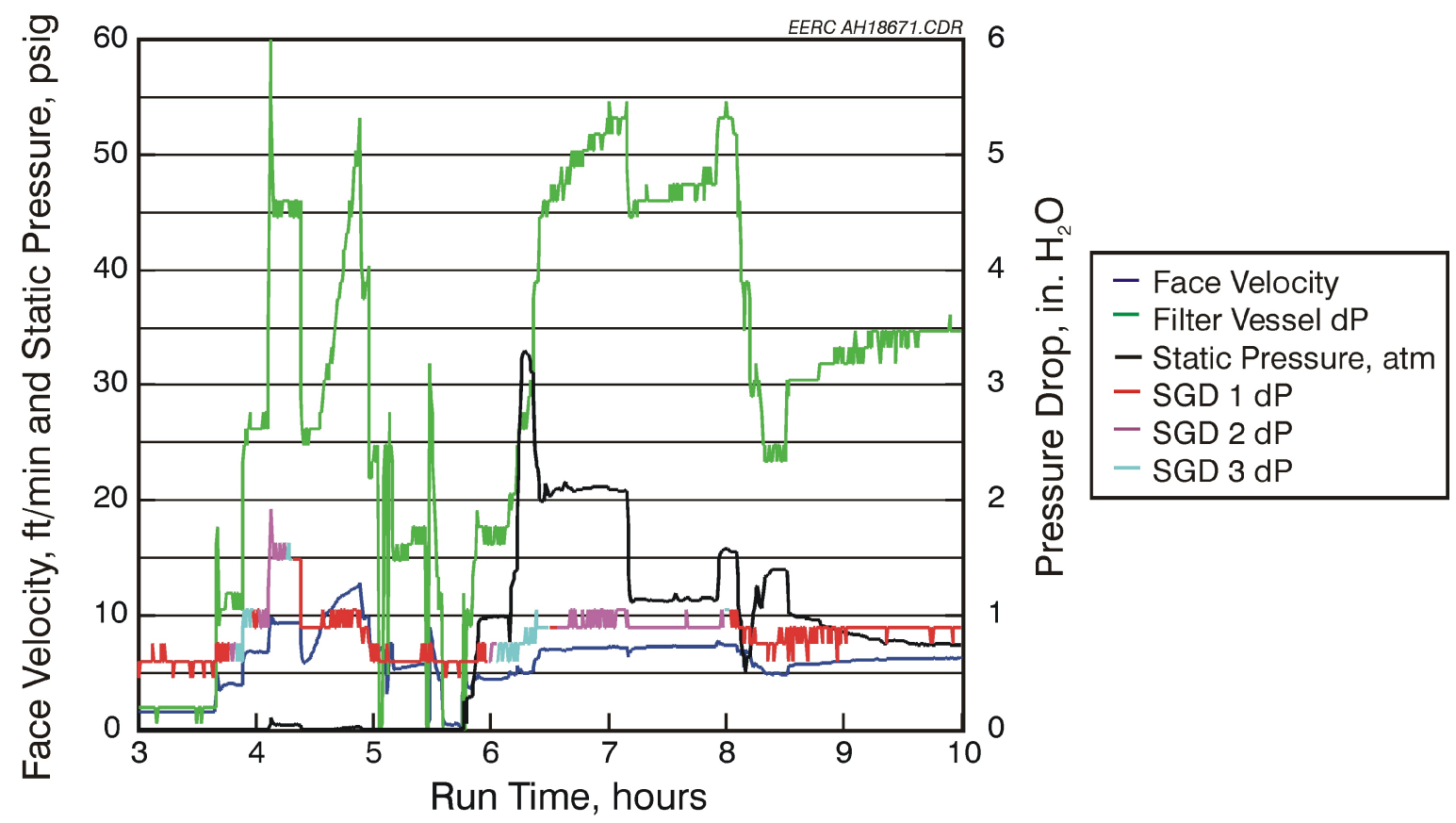

Figure 22. The filter vessel static pressure, differential pressures, and candle filter face velocity for the baseline tests.

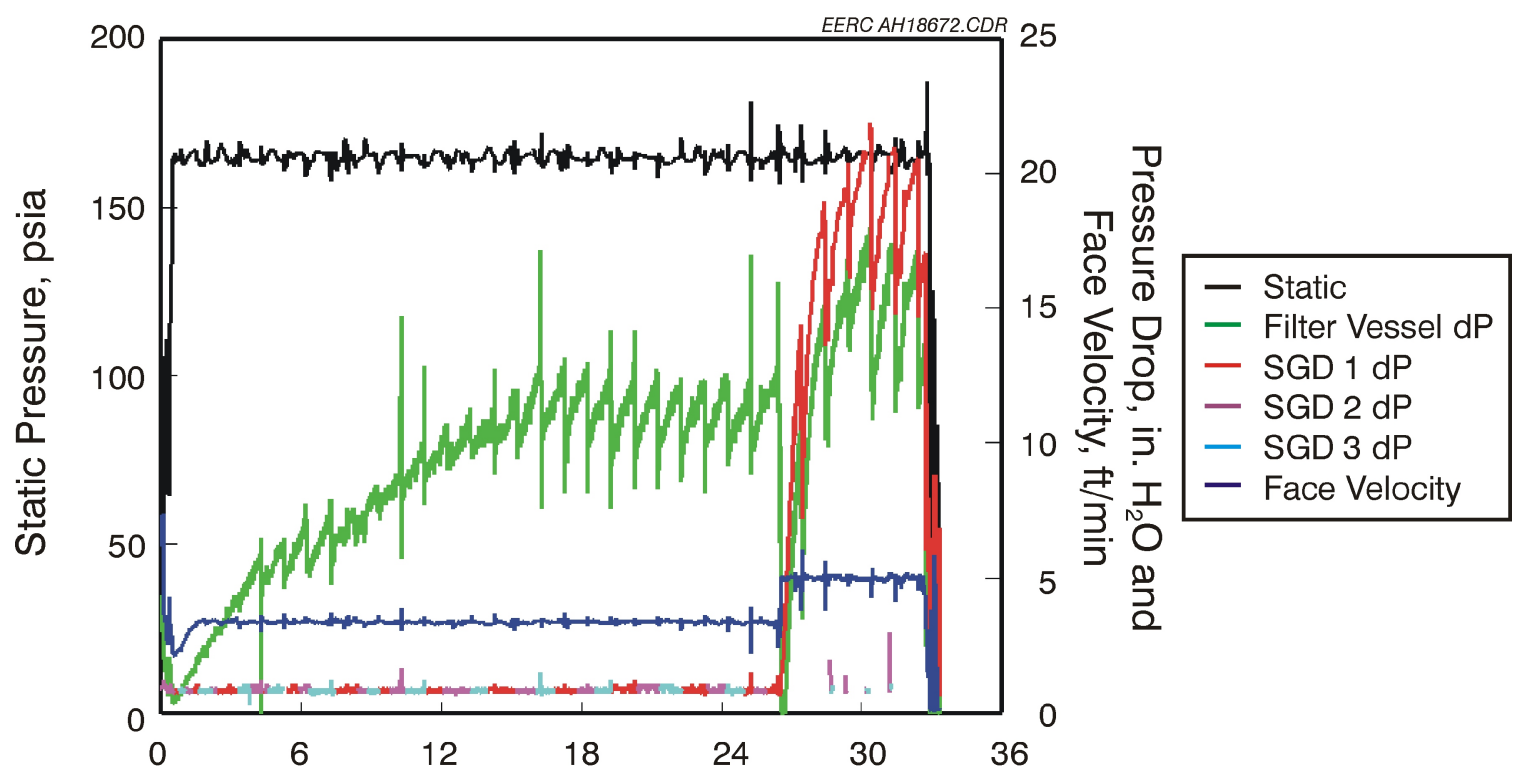

Run Time, hours

Figure 23. The filter vessel differential pressures and candle filter face velocity while firing coal during the February test. 
10 in. $\mathrm{H}_{2} \mathrm{O}(18.7 \mathrm{mmHg})$ during this test, whereas the 60-ppi SGD tested in December took only 11 minutes. Both the SGD and filter vessel differential pressures displayed a sawtooth pattern every 60 minutes, varying about 5 in. $\mathrm{H}_{2} \mathrm{O}(9 \mathrm{mmHg})$ with each backpulse sequence. Gradually the baseline differential pressure (that measured after backpulsing) across the filter vessel reached about 17 in. $\mathrm{H}_{2} \mathrm{O}(32 \mathrm{mmHg})$, which is slightly higher than when one candle was broken during the December test.

Over the course of the day after the candle was broken, the pressure transmitter was switched to SGDs 2 and 3 to verify that they were handling the increase in flow. There was no noticeable increase in the pressure drop across these SGDs after the candle was broken. Particulate sampling was completed 6 hours after the candle was broken, and the test was terminated at that time. Because of a limited supply of candle filters available, a second candle filter was not broken during this test.

During the February tests, a TSI (6) aerodynamic particle sizer (APS) was used to gather realtime particle-size distributions and dust loadings downstream of the SGDs. The system uses a dilution system and a pressure reducer to condition the pressurized flue gas for measurement. Figures 24 and 25 show the dust loadings and particle-size distributions as measured by the APS during the February test. Note that the data produced by the APS are not absolute since they make some assumptions based on particle densities and aerodynamic properties. Baseline APS data indicate a particle loading of $0.01-0.2 \mathrm{mg} / \mathrm{m}^{3}$ before the candle was broken. Two minutes after breaking the candle, a dust loading of $281 \mathrm{mg} / \mathrm{m}^{3}$ was measured, indicating that the 30-ppi SGDs pass a large amount of dust initially. However, 5 hours later, the dust loading was still $40 \mathrm{mg} / \mathrm{m}^{3}$ even though the pressure drop across the SGD had increased considerably. In addition, after each backpulse the amount of dust passing the SGD increased by a factor of 3. This shows that although the SGD was plugging, it was still passing an unacceptably large amount of dust. Figure 25 shows that the dust

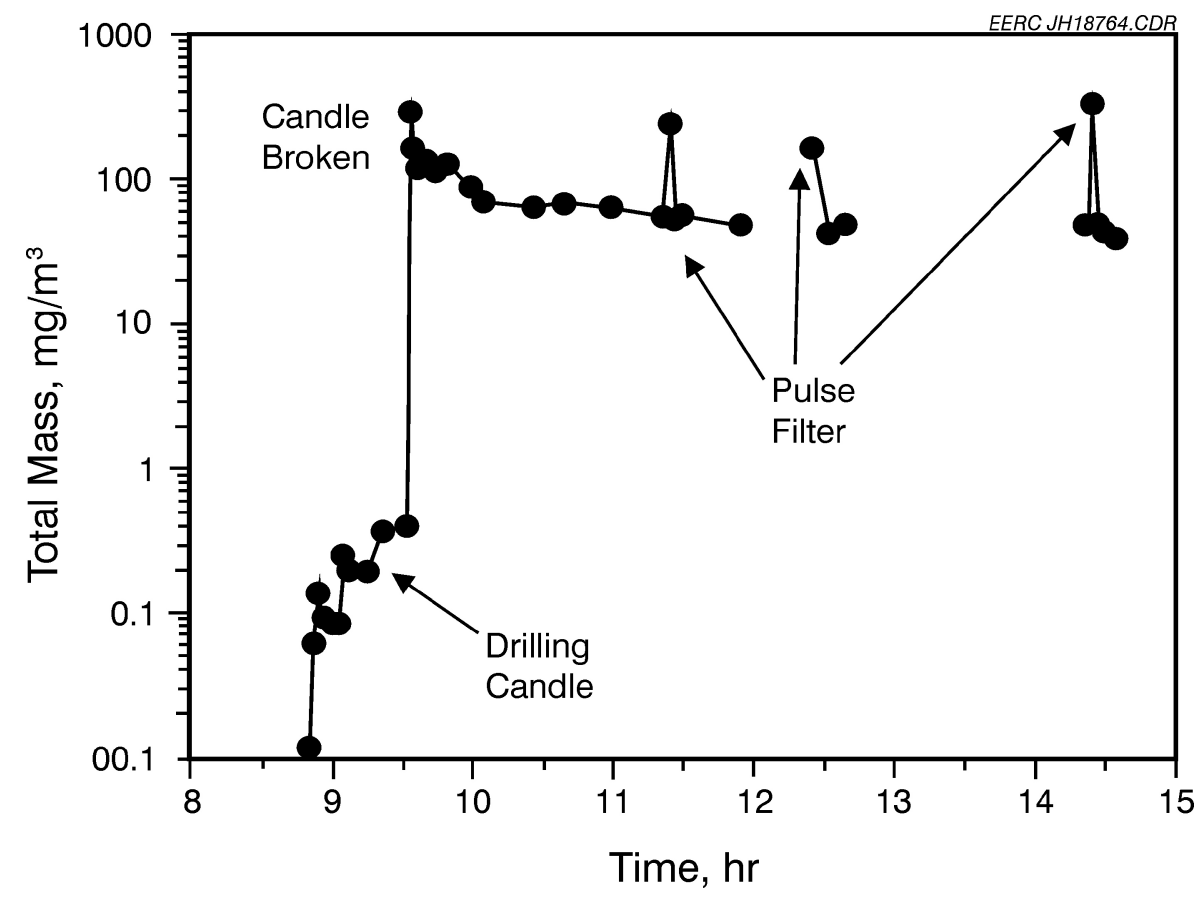

Figure 24. Dust loadings downstream of the SGDs as measured by the APS system. 
passing the SGD was also relatively large. Before breaking the candle, the entrained dust had a mass median diameter of less than 5 microns. After breaking the candle, the mass median diameter increased to an unacceptable 9 microns, slowly declining to 8 microns over 5 hours.

\section{Gasification Testing}

Originally a third bench-scale test of the combustion SGD design had been planned, and the gasification SGD was to be tested without control on the TRDU. However, discussions with the U.S Department of Energy (DOE) technical representative indicated that in the future the transport reactor being tested at the PSDF will be operated only as a gasifier. Therefore, we suggest performing future bench-scale tests only with the gasification SGDs in the EERC continuous fluidbed reactor (CFBR). The CFBR is of a similar size to the PFBR and uses the same filter vessel, but is designed for operation as a bubbling bed gasifier.

Figure 26 shows the 4-lb/hr CFBR that was used for the gasification test. The unit was originally designed as a pyrolysis unit for a DOE mild gasification program, but has since been used for gasification and pyrolysis on a variety of projects. Gas used for fluidization is mixed in a gas manifold. Bottled gas, house nitrogen, house air, and any liquid desired (such as water) are first preheated, then mixed, and heated to reaction temperature in a superheater. Two bottled gases in combination with either house air or house nitrogen and a liquid can be used at the present time.

The reactor is constructed of $316 \mathrm{H}$ stainless steel Schedule 80 pipe. The first (bottom) section is made of 3 -in. $(7.6-\mathrm{cm})$ pipe and is $33 \mathrm{in}$. $(84 \mathrm{~cm})$ long. The next (top) reactor section is made of 4-in. $(40-\mathrm{cm})$ pipe 18.75 in. $(47.625 \mathrm{~cm})$ long. The two sections are connected with a $316 \mathrm{H}$ weld reducer. The unit was designed such that the top of the fluid bed lies $33 \mathrm{in}$. $(84 \mathrm{~cm})$ above the coal

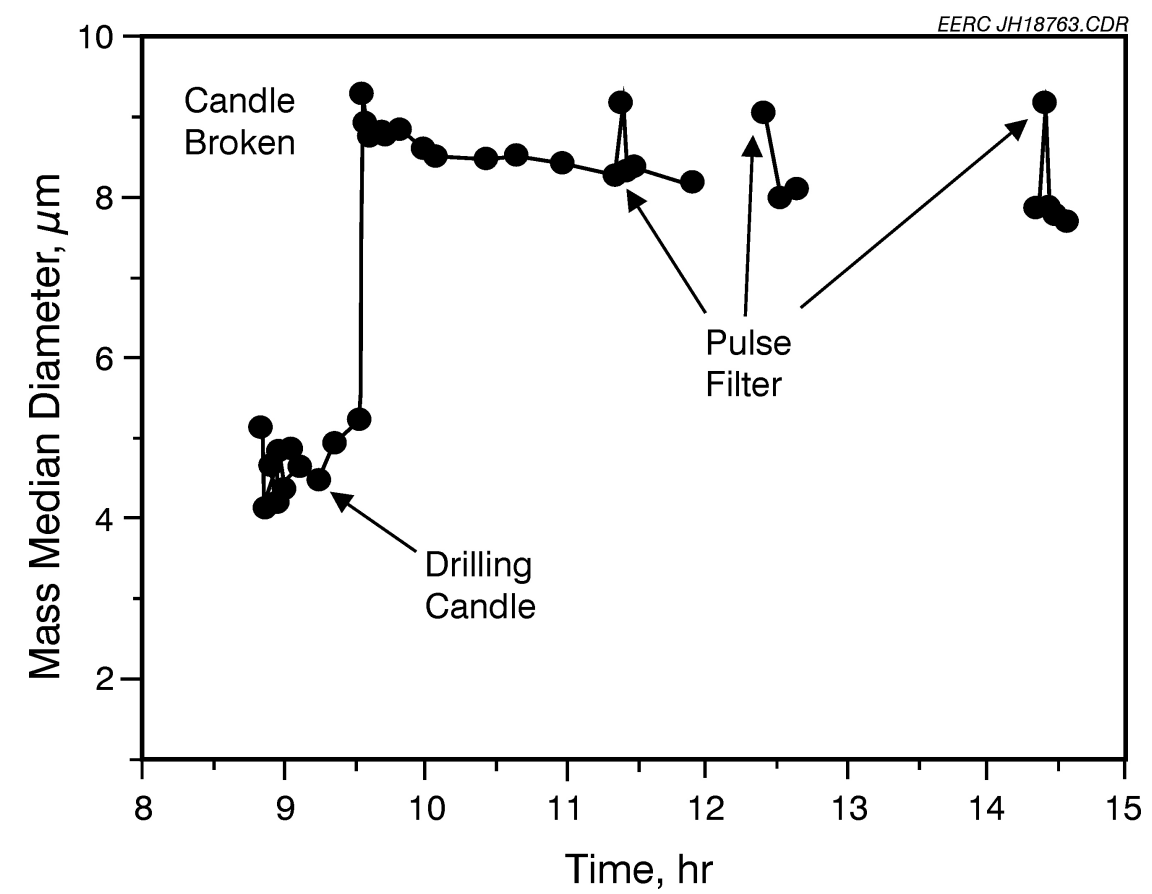

Figure 25. Particle-size distributions downstream of the SGDs as measured by the APS system. 


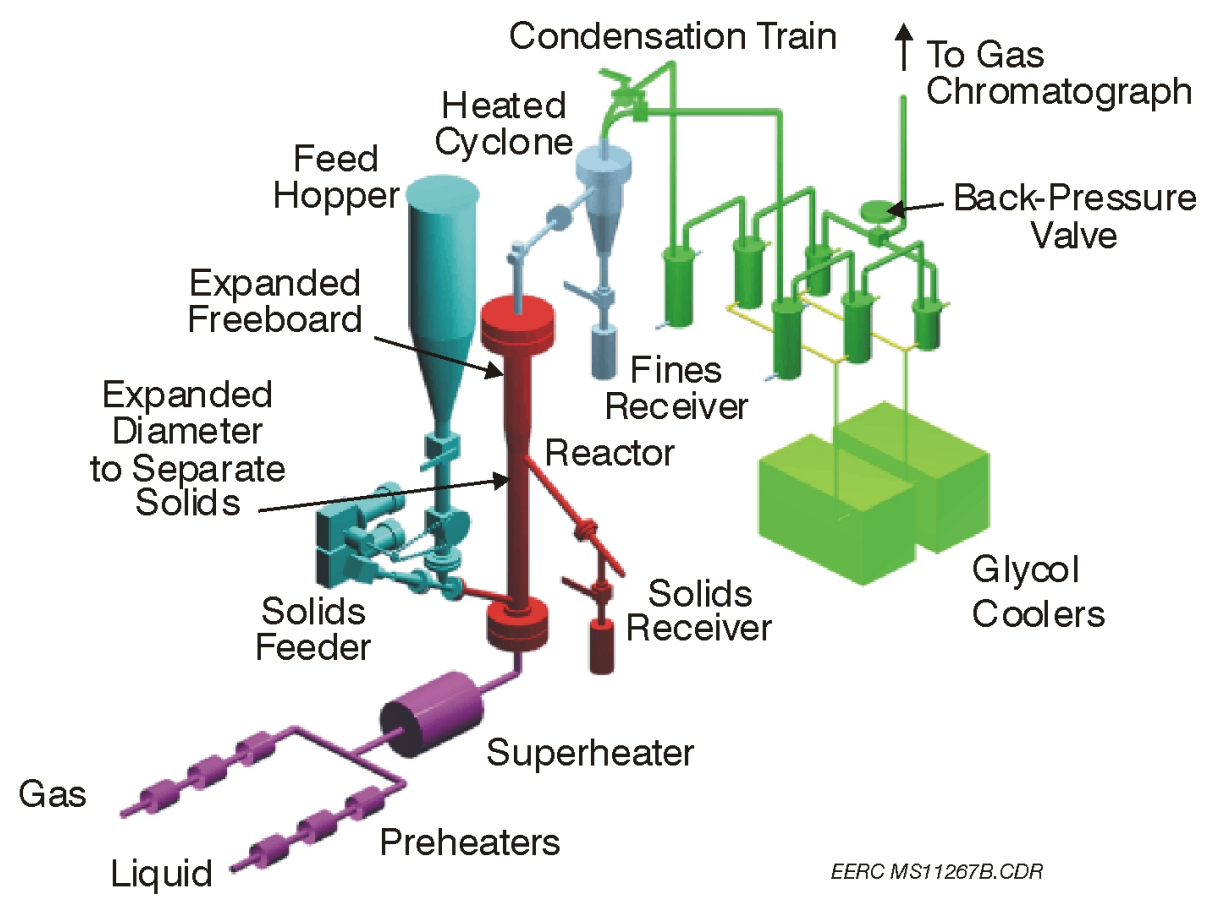

Figure 26. Schematic of the 4-lb/hr CFBR for testing of the gasification SGD.

injection point. A solids off-take leg at the top of the bed is the primary means of solids removal from the reactor. A ball valve facilitates the collection of product while the system is operating. The reactor currently has two ceramic fiber heaters to maintain the vessel's temperature and eliminate hot spots. Using external heaters allows the evaluation of internal and external heating methods for process development and scaleup. The reactor is capable of operation at a maximum of $155 \mathrm{psig}$ $(11.5 \mathrm{~atm})$ and $1550^{\circ} \mathrm{F}\left(840^{\circ} \mathrm{C}\right)$.

A 3-in.(7.6-cm)-diameter cyclone is used for solids removal from the gas stream. A ball valve allows the changing of the solids catch pot while the system is operating. The cyclone is heated with a ceramic fiber heater capable of operating at a temperature of $1650^{\circ} \mathrm{F}\left(900^{\circ} \mathrm{C}\right)$ and $200 \mathrm{psia}$ (13.6 atm). An 8-in. (20.3-cm)-long section of 2-in. 316H stainless steel Schedule 80 pipe has also been utilized as a pressure vessel to either contain a fixed bed of a zinc-based sorbent to reduce the $\mathrm{H}_{2} \mathrm{~S}$ concentrations or to contain a calcium-based sorbent for the removal of chlorine gases from the fuel gases. Typical CFBR operating conditions are shown in Table 5.

Three 4-in. (10.1-cm)-diameter vessels are used to remove all condensables from the gas stream. Two separate trains were installed: one for mass balance sampling and the other for heatup, unsteady-state conditions, and cooldown. The first condenser pot is indirectly cooled by water and typically cools the gas stream from $570^{\circ} \mathrm{F}\left(300^{\circ} \mathrm{C}\right)$ to $200^{\circ} \mathrm{F}\left(95^{\circ} \mathrm{C}\right)$. The next two condensers, also indirect, are glycol-cooled. The exit gas temperature is typically $50^{\circ} \mathrm{F}\left(10^{\circ} \mathrm{C}\right)$. A glass wool filter was used to capture aerosols passed through the condenser system. A wet scrubber has also been used to neutralize any chlorine still present in the gas stream before the gas is sent through a product gas meter. 
Table 5. Typical CFBR Operating Conditions.

\begin{tabular}{|c|c|c|}
\hline Reactor Diameter & & 2.9-in. $(7.4-\mathrm{cm})$ i.d. \\
\hline Temperature & & $1300^{\circ}-1500^{\circ} \mathrm{F}\left(700^{\circ}-815^{\circ} \mathrm{C}\right)$ \\
\hline Pressure & & $0-175$ psig (1-12.9 atm) \\
\hline Gas Flow Rate & & $1-10 \mathrm{scfm}(28-283 \mathrm{slpm})$ \\
\hline Coal Feed Rates & & Nominally $4 \mathrm{lb} / \mathrm{hr}(1.8 \mathrm{~kg} / \mathrm{hr})$ \\
\hline Velocities & & $1.5-2 \mathrm{ft} / \mathrm{sec}(46-61 \mathrm{~cm} / \mathrm{sec})$ \\
\hline Cyclone Exit Temperature & & $1475^{\circ} \mathrm{F}\left(800^{\circ} \mathrm{C}\right)$ \\
\hline Particulate Loading & & $300-4000 \mathrm{ppm}$ \\
\hline Typical Gas Composition & Raw Gas & Without Fluidizing $\mathrm{N}_{2}$ \\
\hline $\mathrm{CO}_{2}$ & 4.68 & 26.56 \\
\hline $\mathrm{CO}$ & 2.67 & 15.16 \\
\hline $\mathrm{H}_{2}$ & 7.69 & 43.62 \\
\hline $\mathrm{CH}_{4}$ & 1.01 & 5.74 \\
\hline $\mathrm{N}_{2}$ & 83.45 & \\
\hline
\end{tabular}

A Genesis software package is used for process control and data acquisition. Pressure drop across the bed is measured by two transmitters, and thermocouples throughout the unit measure temperatures. Temperature and pressure readings are recorded every 30 seconds, and these data are directly transferred to Lotus spreadsheets. An on-line Foxboro 931C gas chromatograph together with some gas bag samples to be analyzed by an HP 5880 gas chromatograph are used for measuring gas compositions. If desired, the gas composition of the coal-derived gas stream can be adjusted slightly by adding some bottled gas to the gas stream entering the reactor.

The February 2001 PFBR test showed that a 30-ppi disk, even when coated with a sticky material, still had pores too large to work effectively as an SGD. Therefore, it is expected that the 30-ppi SiC disks currently prepared for use in the gasification SGD will also behave poorly. PorvairSelee has indicated to us that it will not be possible to make $\mathrm{SiC}$ disks with a finer pore size. However, they are willing to attempt to make 60-ppi disks from silica-bonded fused-silica grains which will satisfy the requirement that the material be based on silica. Two dozen of these were ordered of two different densities, but it was found that the pressure drop across the disks was much too high. The high pressure drop was primarily due to blockage of gas pathways by thin skins of ceramic caused by an excessively viscous aqueous ceramic slurry used to coat the polymer sponges. After discussing the problem with Porvair-Selee representatives, they decided to attempt to make 60-ppi SiC disks for us. Two dozen of these were ordered of two densities and were found to have very low pressure drops, only around 3 to 5 in. $\mathrm{H}_{2} \mathrm{O}$ (7.6 to $12.7 \mathrm{mmHg}$ ) at $25 \mathrm{scfm}(708 \mathrm{slpm})$ airflow. Several of the disks were lithiated to make them sticky under gasification conditions, and in September, two of them were tested in the filter vessel while operating with the CFBR.

Coal feed, steam flow, and airflow were initiated at about 9:00 a.m. September 13. The overall filter vessel differential pressure increased very slowly over the course of the day, and there was no increase in differential pressure across either of the SGDs. Backpulsing the candle filters had no apparent effect on the performance of the SGDs, although the pressure drop across the filter vessel dropped dramatically, and filter vessel differential pressure was very slow to increase again. 
The test plan called for 24 hours of gasification before breaking the candle filter; however, difficulties with the computer running the data acquisition system necessitated several forced shutdowns on the evening of the 13th. The interruptions had no apparent effect on the performance of the candle filters or fail-safe devices. The computer problems were remedied and the unit successfully restarted, but several hours of baseline data (prior to breaking the candle) were lost.

After 19 hours of coal firing, the coal feed rate was increased in an attempt to accelerate the rate of differential pressure increase across the candle filters prior to breaking a candle. The candle was then broken. A drill bit was installed in a flange in the side of the filter vessel at the time the candles were installed; this could be operated while the system was at pressure, to drill a hole in the candle nearest the flange. In this case, the candle could not be drilled, and a hammer was used to drive the drill bit into the candle.

The differential pressure across the filter vessel dropped from about 15 to 0 in. $\mathrm{H}_{2} \mathrm{O}$ ( $28.0 \mathrm{mmHg}$ ) when the candle broke; over the next 4 hours, it only increased to about $0.75 \mathrm{in} . \mathrm{H}_{2} \mathrm{O}$ $(1.4 \mathrm{mmHg}$ ). The differential pressure across the fail-safe device increased slightly, from about 0.4 to 2 in. $\mathrm{H}_{2} \mathrm{O}(0.7$ to $3.7 \mathrm{mmHg})$ during that same time period.

An hour-long baseline particulate sample was taken at the filter vessel outlet prior to breaking the candle. A second sample, lasting 20 minutes, was initiated as soon as the candle broke, and a 40-minute sample was begun 35 minutes after the candle was broken. A final sample was taken near the end of the test, lasting 60 minutes. All samples showed no reduction in particulate loading that could be attributed to plugging of the SGD.

Over the course of the day, the pressure transmitter was switched to the SGD associated with the unbroken candle. Consistent with the minimal pressure drop seen across the entire filter vessel, the differential pressure across the associated SGD was 0, even lower than it was before the candle was broken. Postrun maintenance included the removal of the filter vessel top. Inspection of the filter vessel showed a layer of ash on top of the tube sheet and SGDs; there was no evidence of ash leaking around the gaskets sealing the candles to the tube sheet. All results indicate that the gasification SGD plugged only slightly, if at all, after the candle filter was broken.

Analyses of the filter and cyclone dust indicate that it is primarily carbon, with losses on ignition of $50 \%$ to $70 \%$ for samples upstream of the SGD and $57 \%$ for a sample collected from the surface of the tube sheet (indicating that it had passed through the SGD). The particle-size distributions determined by Malvern analysis indicate that the filter vessel dust has a mass median diameter of approximately $8 \mu \mathrm{m}$, whereas the dust passing through the SGDs had a mass median diameter of approximately $9 \mu \mathrm{m}$. Optical microscopy shows that the particles fully permeated the SGD above the broken candle filter, indicating that the penetration of dust was due to failure of the SGD to trap the dust, not the failure of a seal.

Samples of the filter vessel dust collected from the vessel hopper were sieved into \pm 325 -mesh (45-micron) samples and analyzed separately. Sieving of the hopper dust had to be performed because not enough dust which had passed through the SGD was available for the analyses. This sieve size was chosen because most of the particles larger than this tend to settle into the hopper 
upon entering the filter vessel, while the smaller particles are more likely entrained through the hole left by a broken candle and into the SGD (note that this is a very rough estimate of the size split and that it varies considerably with fuel, sorbent, and operating conditions).

Analyses of the sieved CFBR filter hopper dust showed no significant difference in loss on ignition between the larger and smaller fractions. Both were just under $50 \%$. A portion of the weight loss was due to carbon combustion, and most of the rest of the loss was due to calcination of the unreacted dolomite used as a sulfur sorbent in the bed. Computer-controlled scanning electron microscopy (CCSEM) of the mineral grains in the -325 -mesh dust show that $14 \%$ of the mineral grains are unreacted dolomite sorbent, and $44 \%$ is mixed sorbent and coal minerals such as kaolin, quartz, sulfidized dolomite, and partially desulfurized pyrite. The remainder of the minerals are individual mineral grains of the same types found in the mixed particles. Similar types of minerals were found in the dust found in the filter vessel after the test of the combustion SGD, except for much less unreacted sorbent in the combustion dust. Over $80 \%$ of the mineral grains in the gasification dust are less than 10 microns in diameter, whereas in the combustion test dust just over $50 \%$ was less than 10 microns in diameter, although $83 \%$ was less than 22 microns in diameter. However, the CCSEM cannot distinguish carbon particles, so separate SEM observations were performed, indicating that a large fraction of the -325 -mesh dust in the gasification dust is unreacted carbon particles with diameters below 10 microns. They appear quite angular and so are likely to be unreacted coal as compared to carbonaceous particles formed from the gas phase through a reverse Boudouard reaction.

These analyses indicate that part of the reason that the dust may not have stuck in the gasification SGD was because it was smaller and could more easily pass through the SGD without being caught in the pores. Also, the gasification dust was composed of much more carbon than the combustion filter dust, and the carbon is likely to be less wetted by the sticky coating. In addition, the viscosity of the sticky coating used in the gasification SGD was much higher than that used in the combustion SGD, which may have prevented the gasification coating material from thoroughly wetting the dust. This suggests that a lower-viscosity, better-carbon-wetting sticky coating may be more successful than the current material.

\section{CONCLUSIONS}

The initial hypothesis of the work was that upon breakage of a filter the adhesive coating would trap larger dust particles within the interpore openings of the ceramic substrate to block further dust flow through the SGD. To prevent the particles from beingblown out of the device upon backpulsing, it was believed that the coatings should be either viscous or reactive with the dust to form a solid bond. To assure the long life of the coatings, it is necessary that they either have very low vapor pressures and reactivities with the gas stream or that the gas stream is already saturated with the components of the coating. Therefore, two coatings were developed. The one for gasification conditions is a viscous lithium silicate with a low vapor pressure. For combustion conditions, a low-viscosity potassium-magnesium sulfate material was developed which would react with larger limestone sorbent particles to form a solid to lock the particles in place. The combustion adhesive coating was based on materials that are known to be sticky and commonly exist in filter 
dust from coal-fired systems. The natural occurrence of the adhesive components in filter dust assures that they are saturated within the gas stream and so will not evaporate or change chemical form. The SGDs were tested in a bench-scale hot-gas filter system connected to both pressurized fluidized-bed combustion and gasification systems.

Tests in the bench-scale reactors showed that the combustion SGDs covered with the lowviscosity adhesive coating worked very well, plugging within minutes of a filter break. Only the bottom third of the SGD was filled with ash before plugging, indicating that very little dust would pass to the turbine in a power system. However, the more viscous coating used on the gasification SGD was not effective in trapping dust and blocking the gas and dust flow through the broken candle orifice.

The bench-scale tests of the SGDs showed that a porous ceramic substrate need only exhibit a pressure drop of 2 in. $\mathrm{H}_{2} \mathrm{O}(3.7 \mathrm{mmHg})$, and it will still plug rapidly if an adhesive coating is applied to its surface. However, the adhesive is most effective if it has a low viscosity and wets the dust particles. SEM analyses indicate that the pore openings are not plugged with small numbers of large particles. Instead, large numbers of small particles derived from coal minerals fill the pore and are likely coated with the low-viscosity adhesive. The coating causes them to agglomerate within the pore so that they are not removed on reverse pulse cleaning and also prevents other particles from passing through the SGD. For the gasification SGD, a low-viscosity coating that is thermodynamically stable in the gas stream must be developed.

\section{LIST OF ACRONYMS}

$\begin{array}{ll}\text { APS } & \text { aerodynamic particle sizer } \\ \text { CCSEM } & \begin{array}{l}\text { computer-controlled scanning electron microscopy } \\ \text { CFBR }\end{array} \\ \text { continuous fluid-bed reactor } \\ \text { DOE } & \text { U.S. Department of Energy } \\ \text { EERC } & \text { Energy \& Environmental Research Center } \\ \text { EPA } & \text { U.S. Environmental Protection Agency } \\ \text { IGCC } & \text { integrated gasification combined cycle } \\ \text { PFBC } & \text { pressurized fluidized-bed combustor } \\ \text { PFBR } & \text { pressurized fluidized-bed reactor } \\ \text { ppi } & \text { pores per inch } \\ \text { PSDF } & \text { Power Systems Development Facility } \\ \text { SEM } & \text { scanning electron microscope } \\ \text { SGD } & \text { safeguard device } \\ \text { TGA } & \text { thermogravimetric analysis } \\ \text { TRDU } & \text { transport reactor development unit } \\ \text { ZTA } & \text { zirconia-toughened alumina }\end{array}$




\section{REFERENCES}

1. Lippert, T.E.; Bruck, G.J.; Sanjana, Z.N.; Newby, R.A. Westinghouse Advanced Particle Filter System. In Proceedings of the Advanced Coal-Fired Power Systems '95 Review Meeting Vol. I; DOE/METC-95/1018, Vol. 1 (DE95009732), June 1995; pp 123-139.

2. Phase Diagrams for Ceramists Volume 2; Levin, E.M.; Robbins, C.R.; McMurdie, H.F., Eds.; American Ceramic Society, 1969, p. 253.

3. Shelby, J.E. J. Appl. Phys. 1978, 49, 5885.

4. Hurley, J.P.; Swanson, M.L. Baseline and Optional Bench-Scale Testing of a Chemical Filter Safeguard Device; Report for U.S. Department of Energy Contract No. DE-AC26-99FT40677-03; 2000 .

5. U.S. Environmental Protection Agency Method 5d; www.epa.gov/TTN/EMC/PROGAT.HTML (February 2002).

6. TSI Inc., 500 Cardigan Road, PO Box 64395, St. Paul, MN 55164. 